\title{
Three-Dimensional Numerical Model for Soil Vapour Extraction
}

\author{
V. Th. Nguyen ${ }^{1}$, Lian Zhao ${ }^{2}$ and Richard G. Zytner ${ }^{3 *}$ \\ ${ }^{1}$ Department of Civil and Environmental Engineering, Seoul National University, Korea \\ ${ }^{2} \&{ }^{3}$ School of Engineering, University of Guelph, Guelph, ON, Canada N1G 2W1 \\ *Corresponding Author: rzytner@uoguelph.ca
}

Published Journal of Contaminant Hydrology (2013) 147:82-95

\begin{abstract}
Mass transfer limitations impact the effectiveness of soil vapour extraction (SVE) and cause tailing. In order to identify the governing mass transfer processes, a threedimensional SVE numerical model was developed. The developed model was based on Comsol Multiphysics ${ }^{\circledR}$ a finite element method and incorporates multi-phase flow, multicomponent transport and non-equilibrium transient mass transfer. Model calibration was done against experimental data from previous lab-scale reactor experiments and a previously remediated site.
\end{abstract}

The developed model, 3D-SVE, nicely simulates laboratory findings and allows for changes in the important governing mass transfer relationships. It was seen that a single averaged mass transfer value is a poor representation of the entire SVE operation and that a transient mass transfer coefficient is required to understanding SVE tailing. The laboratory results did not transfer well to the field, showing the presence of scale-up factors that are related to the increased mass transfer resistant taking place. Further research is required to elaborate on this scale-up factor. However, both lab and field scale calibration showed that the most important mass transfer is between NAPL and vapour phase, with the mass transfer coefficient values for aqueous to solid phase, and NAPL to aqueous phase being identical in both scenarios. 
Keywords: Soil vapour extraction, 3D numerical model, multiphase flow, multi-component transport, rate-limited mass transfer.

\section{INTRODUCTION}

Numerical modeling has become an important tool in the development of SVE technology by providing a better understanding of the SVE processes, and enhancement of SVE applications [Harper et al., 2003; Barnes, 2003; Bradner and Murdoch, 2005; Barnes and White, 2006]. A proper numerical model can also assist in the design of an SVE system [Thomson et al., 1997], and help evaluate when SVE should be stopped [Carroll et al., 2012]. Unfortunately, very few models incorporate transient mass transfer processes in a three-dimensional setting, which adversely affects performance. As such, most designs are based on either simple "rule-of-thumb" estimations, analytical approximations or limited simulations, which lead to model deficiencies when simulating real world SVE situations [Rathfelder et al., 2000; Rahbeh and Mohtar, 2007; Brusseau et al., 2010].

Some studies have focused on specific non-equilibrium mass transfer processes in onedimensional (1D) column or two-dimensional (2D) horizontal experiments and numerical investigations [Rathfelder et al., 2000; Abriola et al., 1997; Hoier et al., 2009; Carrol et al., 2012]. However, due to the flow in highly heterogeneity subsurface geological media, 1D/2D models cannot simulate the complex fluid flows and transport processes. Three-dimensional models may produce a markedly improved remediation design due to following reasons. First, modeling in three dimensions may use maximum information available from actual spatially variable characteristics of the subsurface site. Predictions may be improved by using detailed soil 
mapping processes and conducting experiments with contaminated soil. Second, due to the inclusion of SVE configurations and operation conditions, modified multiphase, multicomponent and non-equilibrium three-dimensional models would be possible and more realistic than local equilibrium, one- or two-dimensional models. Third, three-dimensional models can provide a more accurate representation of field settings, despite the requirement for significant input data and a large computational effort.

The ability of a three dimensional SVE model to match real field performance data is the most difficult, specifically within the tailing region [Barnes and White, 2006]. Rate-limited mass transfer is an important factor that impacts tailing [Chai and Muira, 2004 and Gidda et al., 2011], and the efficiency and speed of remediation [Zhao and Zytner, 2008; Carroll et al., 2012]. Accordingly, the inclusion of rate-limited mass transfer coefficients within the $3 \mathrm{D}$ model is paramount to accurately simulating real field scenarios. There have been some multiphase flow and multi-component transport mathematical models dealing with SVE processes incorporating interface mass transfer documented in the literature, such as Sleep and Sykes [1989, 1993], Lingineni and Dhir [1992], Abriola et al. [1997, 1999], Thomson et al. [1997] and Rathfelder et al. [2000].

The USACE [2002] reported several three-dimensional models for soil vapour extraction, but these models have been used only to simulate air flow and design the SVE system by screening the candidacy of a site and arranging the layout of wells. MODFLOW is a threedimensional finite-difference groundwater model; connected to GMS (Groundwater Modeling System). It is often used in SVE simulation assuming a single gas phase flow, whereas water and NAPL phases are immobile. AIR3D was developed to estimate the unsaturated zone permeability from field data obtained from horizontal well SVE tests. AIR3D is an adaptation of 
the groundwater flow code MODFLOW to simulate three-dimensional air flows in a heterogeneous, anisotropic unsaturated zone where air flow is induced through dry wells or trenches, as in vapour extraction remediation. GAS2D and GAS3D are numerical two- and three-dimensional models developed to simulate gas flow conditions under vadose zone conditions. The GAS3D model was verified and validated by comparing the results of the finitedifference solution to actual field measurements and the results of an analytical solution under homogeneous and isotropic conditions without transport of contaminants.

At present time, two commercially available 3-D vapour flow and transport models are VENT3D [Benson, 2011] and SVE-3D [Scientific Software Group, 2011]. A comparison on the ability of the developed model with other 3D numerical models is shown in Table 1.

The 3D model developed in this study simulates multiphase flow in a multi-component transport situation and incorporates non-equilibrium transient mass transfer. The model provides the foundation for more complex simulations like multi-well spacing. Calibration was done against sets of experimental and field observed data using mass transfer coefficients as fitting parameters. A comparison between the numerical results with the experimental data shows a very good agreement. However in the field scale simulation, the comparison between the numerical results with the observation data still shows some differences. Due to the limited amount of field data, it was difficult to carry out an intensive calibration to find the best fitting parameters. Multi-variable sensitivity analysis was also implemented to determine which parameter had the most impact on the simulation, to give a better understanding of the dominant mechanisms contributing to the long tailing effects in SVE operation.

\section{METHODOLOGY}




\subsection{Setting up the 3D-SVE Model}

Using a suitable conceptual model to represent SVE operation is crucial when conducting modeling studies. A typical contaminated site is considered to be a heterogeneous domain. The installation of injection or passive wells improves the flow of fresh air, while sealing the ground surface of a contaminated zone overcomes the by-pass of air flow around the venting well. Threedimensional modeling allows the simulation of a complete SVE system under these practical operational conditions and geological settings.

SVE treatment utilizes the volatile properties of contaminants, whereby mass transfer occurs between the adsorbed, dissolved, and free phases in the soil and vapour phases. The contaminants which are converted into vapour phase will be removed through the venting well and treated aboveground. The numerical model integrates the processes identified in three-phase flow and multi-component compositional transport by incorporating non-equilibrium interphase mass transfer.

Initially, the spilled NAPL present in the soil starts in the pure NAPL phase, (referred to as residual saturation), from which the NAPL may be sorbed on the soil surface, dissolved in the aqueous phase, or volatilised to the soil gas.

Similar to the Michigan soil vapor extraction remediation (MISER) 2D model [Rathfelder et al., 2000], and based on standard macroscopically averaged flow equations [Abriola, 1999], the developed 3D SVE model represents multiphase flow and multi-component behaviour through Equation 1.

$$
\frac{\partial}{\partial t}\left(\varphi \rho_{\beta} S_{\beta}\right)=\nabla\left[\frac{\rho_{\beta} k_{i j} k_{r \beta}}{\mu_{\beta}}\left(\nabla p_{\beta}-\rho_{\beta} g e_{j}\right)\right]+E_{\beta}^{\alpha}+\rho_{\beta} Q_{\beta}
$$

Where 


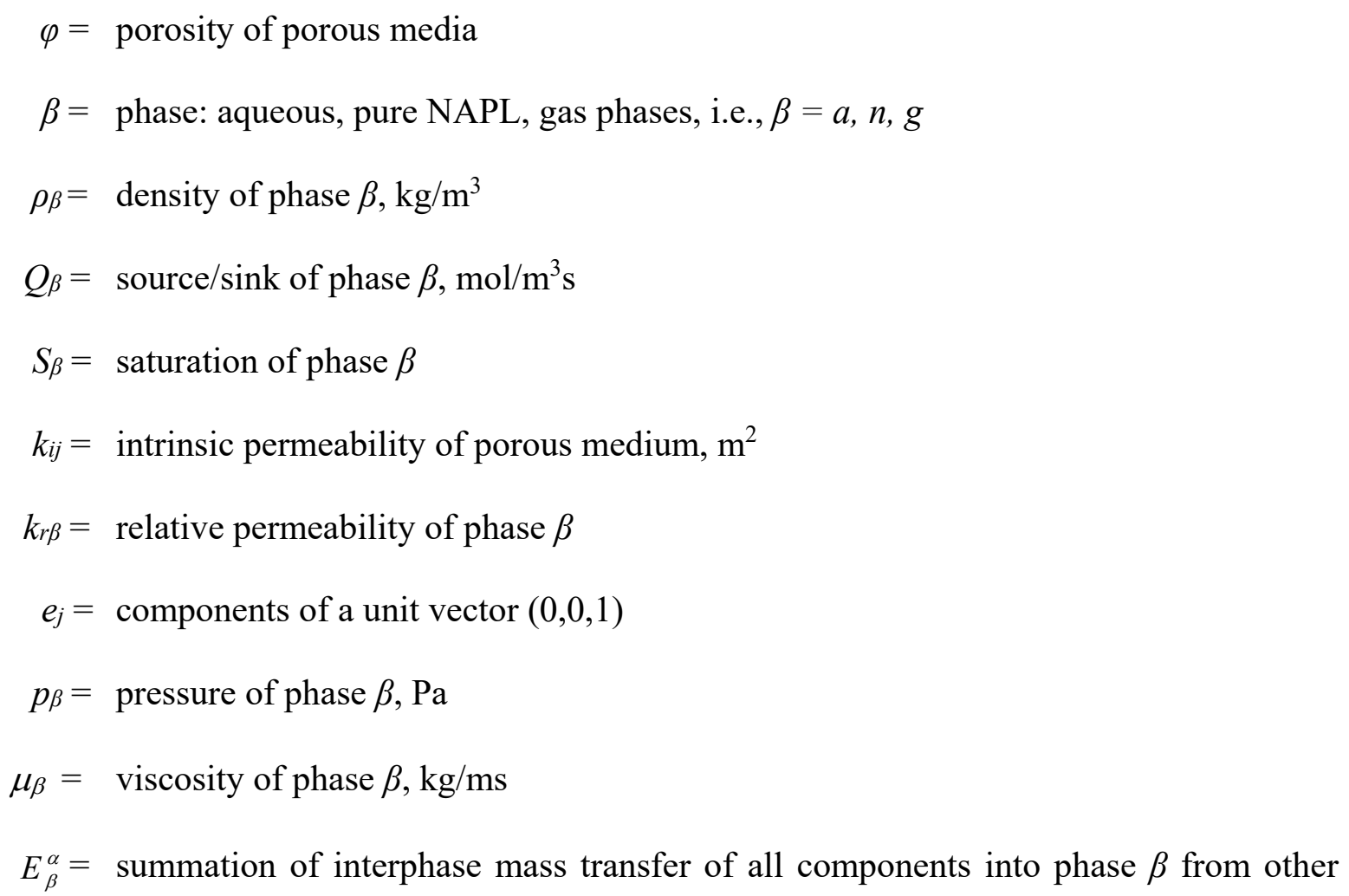
possible phase, $\mathrm{mol} / \mathrm{m}^{3} \mathrm{~s}$, which is the sum of the rate of mass transfer of all components and is expressed as:

$$
E_{\beta}^{\alpha}=\varphi S_{\beta} \sum_{\alpha} \sum_{\beta} \gamma_{\alpha \beta, k}
$$

Where

$\gamma_{\alpha \beta, k}=$ rate of mass transfer of component $k$ between phases $\alpha$ and $\beta\left(\mathrm{mol} / \mathrm{m}^{3} \mathrm{~s}\right)$.

Mass transport in the aqueous, gaseous phase and NAPL phase (if applicable) for each constituent $k$, is assumed to follow the non-linear advective-dispersive conservation formulation [Bear, 1972]. The complete transport equation of a component in a phase is given by Equation 3:

$$
\frac{\partial\left(\varphi S_{\beta} C_{\beta, k}\right)}{\partial t}=\nabla\left(\varphi S_{\beta} D_{\beta k} \nabla C_{\beta, k}\right)-\nabla\left(q_{\beta} C_{\beta, k}\right)+\gamma_{\alpha \beta, k}+Q_{\beta, k}
$$

where

$$
C_{\beta, k}=\text { molar concentration of species } \mathrm{k} \text { in phase } \beta, \mathrm{mol} / \mathrm{m}^{3} \mathrm{~s}
$$




$$
\begin{aligned}
& D_{\beta, k}=\text { dispersion coefficient tensor of component } \mathrm{k} \text { in phase } \beta, \mathrm{m}^{2} / \mathrm{s} \\
& q_{\beta}=\text { flow velocity of phase } \beta, \mathrm{m} / \mathrm{s} \\
& Q_{\beta, k}=\text { source } / \text { sink of a component } \mathrm{k} \text { in phase } \beta, \mathrm{mol} / \mathrm{m}^{3} \mathrm{~s}
\end{aligned}
$$

In order to close the system of Equations (1) and (3) an additional constitutive relationship is used where phase saturations must sum to one:

$$
S_{a}+S_{g}+S_{n}=1
$$

\subsection{Rate of Interphase Mass Transfer}

Equations (1) and (3) are highly non-linear because they take into account various SVE processes that affect the transport of contaminants including advection, dispersion, adsorption, contiguous phase partitioning and rate-limited mass transfer.

The rate of mass transfer couples the phase flow and transport equations. A general form of the first-order driving kinetics expression for the rate of mass transfer in SVE processes is denoted by [Abriola et al., 1999; Rathfelder et al., 2000]:

$$
\gamma_{\alpha \beta, k}=\rho_{\beta} k_{\alpha \beta}\left(x_{\beta, k}^{e}-x_{\beta, k}\right)
$$

where:

$$
\begin{aligned}
& k_{\alpha \beta}=\text { mass transfer coefficient from phase } \alpha \text { to } \beta, \mathrm{s}^{-1} \\
& x_{\beta, k}=\text { molar fraction of component } k \\
& x_{\beta, k}^{e}=\text { equilibrium molar fraction of component } k
\end{aligned}
$$


For SVE operations, experimental and numerical investigations have shown that ratelimited mass transfer causes a long tailing effect after a sharp decrease in offgas concentration [Chai and Muira, 2004]. The main types of mass transfer processes involved in an SVE operation that should be included in a complex numerical model are:

- NAPL phase to vapour phase

- aqueous phase to vapour phase

- NAPL phase to aqueous phase

- aqueous phase to solid phase

The mass transfer coefficient from NAPL to vapour phase (gas) is represented by $k_{n g}$ and has previously been expressed by Yoon et al. [2002] as:

$$
\begin{aligned}
& k_{n g}=a\left(\frac{S_{n}}{S_{n, i}}\right)^{b} \\
& a, b \quad=\text { adjustable fitting parameters } \\
& S_{n} \quad=\text { NAPL saturation at time } \mathrm{t} \\
& S_{n, i} \quad=\text { Initial NAPL saturation }
\end{aligned}
$$

For mass transfer coefficient from the aqueous phase to vapour, $k_{a g}$, Gidda et al. [2011] formulated the following two-parameter expression:

$$
k_{a g}=c\left(C_{a, k}\right)^{d}
$$

where:

$$
\begin{aligned}
& C_{a, k}=\text { concentration of component } k \text { in aqueous phase, } \mathrm{mol} / \mathrm{m}^{3} \\
& c, d=\text { mass transfer empirical constants. }
\end{aligned}
$$


The mass transfer relationships are empirical and are based on the experimental work of Gidda et al. [2011]. The mass transfer coefficient from aqueous to solid (kas) was held constant for all simulations at a value of $3.6 \mathrm{~h}^{-1}$, while the mass transfer coefficient from NAPL to aqueous ( $\left.k_{n a}\right)$ was held constant at $36 \mathrm{~h}^{-1}$. Based on the work of Gidda [2003], it was not decided to include NAPL to sorbed nor vapour to sorbed as both components did not make significant contributions to the off gas concentration. For all simulations, the mass transfer rate between all phase pairs was updated during the SVE process. The 3D model was calibrated against the lab and field data using the mass transfer expressions in Table 2 as the fitting parameters.

In addition to the mass transfer coefficients, a series of constraint relationships and equations of state were necessary. For porous media, the saturation of each phase must sum to one, while the sum of the molar mass fractions of all species in a phase must be one.

The constitutive relationship is an integral part of multiphase flow theory. Non-hysteric capillary pressure-saturation-relative permeability $\left(p_{c}-S-k_{r}\right)$ relationships are typically accepted in multiphase flow modeling because the relationships are less computationally demanding and require fewer data [Miller et al., 1998]. Lenhard and Parker [1987] postulated that the wetability of a three-phase system abides by the following order: water, NAPL, and air. Thus, in a threephase fluid system there are two interfaces present: water-NAPL and NAPL-air. For this model, the van Genuchten [1980] constitutive relationship was used, where the saturation of the aqueous phase is a function of the water-NAPL capillary pressure, whereas the total liquid saturation is assumed to be a function of the NAPL-air capillary pressure. For calculating the effective saturation in a three-phase system, the relationships proposed by Lenhard and Parker [1987] were used. 
Assuming that only the gas phase is mobile, the water and residual NAPL are considered immobile phases and are regarded as residual saturation. When modeling multiphase flow in the vadose zone, the gas phase is frequently assumed to be the only actively flowing phase [Looney and Falta, 2000]. Van Dijke et al. [1995] used the mixed form of the Richards equation for both water and air phases to describe an interactive movement of the fluids in a porous medium.

\subsection{Dispersion and Dispersion Coefficient Tensor}

Mechanical dispersion is caused by heterogeneities in the subsurface, including the presence of a pore system, and variations in local velocities along tortuous flow paths [Schwartz and Zhang, 2003]. Since mechanical dispersion and molecular diffusion lead to concentration variations in the subsurface, modeling a heterogeneous system using inaccurate estimations of dispersion and diffusion can have a significant impact on the accuracy of the output of the numerical model. As a result, it is necessary to accurately estimate these transport mechanisms for the purpose of model application.

Estimating dispersivity is a difficult task, especially for three-dimensional flow, given by the complexity of a porous media [Zou and Parr, 1993]. To date, this is one of the most poorly developed areas in SVE transport modeling. For the purpose of applying this 3-D SVE model, data obtained from Gidda et al. (2006) was used as similar soils were tested. Gidda et al. (2006) measured the dispersivity of various soils using sulphur hexafluoride ( $\left.\mathrm{SF}_{6}\right)$, an inert tracer, and subjecting the soils to normal SVE operational conditions. For Ottawa sand (a uniform soil) and Brookston soil (a complex soil), the water content and velocity ranged from 0 to $40 \%$, and 0.6 $\mathrm{L} / \mathrm{min}$ to $20 \mathrm{~L} / \mathrm{min}$, respectively. These conditions coincided with a longitudinal dispersivity in 
the range from $0.006 \mathrm{~m}$ to $0.024 \mathrm{~m}$. Applying these trends, lab longitudinal dispersivity value was set at $0.0037 \mathrm{~m}$, while for the field setting it was set at $0.06 \mathrm{~m}$.

In the current model, the relationship between the longitudinal and transversal dispersivity was expressed as:

$$
\alpha_{L}=\alpha_{T H}=10 \alpha_{T V}
$$

Where

$$
\begin{aligned}
\alpha_{L} & =\text { longitudinal dispersivity, } \mathrm{m} \\
\alpha_{T H} & =\text { transversal dispersivity in horizontal direction, } \mathrm{m} \\
\alpha_{T V} & =\text { transversal dispersivity in vertical direction, } \mathrm{m}
\end{aligned}
$$

Dispersivity was held as a constant during the model runs. The same was true for relative permeability.

The multiphase flow and multi-component contaminant transport governing equations, which are the partial differential equations, together with additional constraint relations plus simplifying assumptions, including initial and boundary conditions, can be solved in threedimensional space and time for lab-scale and field-scale scenarios.

\section{Numerical Simulation of the 3D-SVE-L/F models}

Simulation was completed by applying the general SVE numerical model to SVE settings at lab and field scales. For both lab-scale (3D-SVE-L) and field-scale models (3D-SVE-F), the following methodology steps were applied. First, the physical properties of lab and field SVE modeling scenarios and the relevant conceptual models are defined, including the geometry of the simulated domains. Second, the corresponding input parameters as well as boundary and initial conditions are illustrated. The numerical models were calibrated against lab-scale experimental 
and actual field SVE sampling data by adjusting two empirical mass transfer parameters. This allows the time-variant mass transfer coefficients to be determined through the corresponding calibrations. Finally, by implementing the calibrated model, the distribution of pressure, gas saturation levels and concentration of contaminants are examined, so that the accuracy of the modeling studies can be illustrated.

The numerical simulations for the developed 3D-SVE model were implemented using Comsol Multiphysics ${ }^{\circledR}$ (2006), which interfaces with MATLAB [2006], and uses advanced finite element numerical discretization. One of the main reasons for selecting Comsol Multiphysics ${ }^{\circledR}$ was the ability to easily modify the mass transfer expressions and adjust mesh and time step sizes for stability.

Mesh sizing is an important component of numerical modeling as element sizes influence the convergence and accuracy of the solution. A finer mesh always is better, but consequently requires more computer capacity and longer computational time. Comsol Multiphysics ${ }^{\circledR}$ provides for automatic mesh generation to provide efficient idealization of complex domains, where Comsol Multiphysics ${ }^{\circledR}$ adapts different element sizes in different regions of a simulated domain. Accordingly, several mesh resolutions were tried to find an optimum mesh size for the numerical simulation. Comsol Multiphysics ${ }^{\circledR}$ handles time discretization by an implicit scheme with backward differentiation. Generally, a small time step is important for the calculation of the flow field and the transport of contaminants. However, due to the consumption of computational time, the optimal time steps for stable solutions following automatic meshing, were $1 \mathrm{~h}$ in the SVE-L model, and $1 \mathrm{~d}$ in the SVE-F model.

\subsection{SVE Lab-Scale Modeling}


In this section, the lab-scale SVE is simulated based on a series of lab SVE experiments completed by Duggal and Zytner [2009]. These experiments were conducted under various air flow rates for two types of soils (Ottawa sand and Elora silt loam). The geometry of this reactor is shown in Figure 1, where the radius of the venting well $r_{w}$ is $0.025 \mathrm{~m}$, with the radius and height of the reactor $1 \mathrm{~m}$ and $0.23 \mathrm{~m}$, respectively. The screened venting well induces flow through the cylindrical reactor, which contains contaminated soil mixed with toluene. Both the top and bottom ends of the cylindrical reactor have impermeable seals to ensure no short circuiting. The lateral fine-screened metal wall is open to the atmosphere and supports soil away from the wall. The radial air flow comes from the outer radius and flows toward the extraction well in the centre of the reactor. This reactor configuration simulates a field situation with a covered surface (asphalt) and impermeable bottom (bedrock or some other impervious layer).

A heterogeneous soil profile would be ideal to allow better transfer of the lab results to the field, however, due to experimental limitations of acquiring a large volume of undisturbed soil, a homogenous soil profile was used. Both soil types were mixed with toluene to the desired total petroleum hydrocarbon (TPH) content, accounting for volatilization losses, in advance of placing the soil homogeneously in the reactor. Table 3 gives the properties of the soils studied.

The Ottawa Sand experiments had an average starting concentration of 0.023 gtoluene $/ \mathrm{gdry}_{\text {soil }}$ after correcting for handling losses, while the Elora Silt Loam had an average starting concentration of $0.026 \mathrm{~g}_{\text {toluene }} / \mathrm{g}_{\mathrm{dry}}$ soil after correcting for handling losses. The concentrations of toluene in the reactor off gas were used as concentration before and after the SVE run. Analysis of the data by Duggal and Zytner (2009) in terms of mass balance and flow regime did not reveal any short circuiting along the walls of the reactor. 
During the venting process, advection and dispersion mass transport occurred in the mobile gas phase, with volatilization, dissolution, adsorption and partitioning between the aqueous and vapour phases happening in the presence of the residual immobile NAPL phase. All mass transfer processes are assumed to be rate-limited.

The maximum negative pressure, which is the difference between vapour pressure and ambient pressure in the extraction well, is approximately proportional to possible blower capacity (Chai and Miura, 2004). Based on the principle of simplistic steady state radial flow for compressible gas, Equation 9 demonstrates the relationship among the venting flow rate, permeability and the specific absolute pressures at the venting well, which are assigned as boundary conditions for the numerical model [Johnson et al., 1990]:

$$
k_{i i}=\frac{\mu_{g} Q}{\pi p_{W} H} * \frac{\ln \left(\frac{r_{w}}{r_{I}}\right)}{1-\left(\frac{p_{a t m}}{p_{w}}\right)^{2}}
$$

where:

$$
\begin{aligned}
k_{i i} & =\text { intrinsic permeability of porous media, } \mathrm{m}^{2} \\
Q & =\text { flow rate of venting well, } \mathrm{m}^{3} / \mathrm{s} \\
p_{W} & =\text { venting absolute pressures on the venting well, } \mathrm{Pa} \\
p_{a t m} & =\text { atmospheric pressure, } \mathrm{Pa} \\
r_{W} & =\text { radius of venting well, } \mathrm{m} \\
r_{I} & =\text { radius of influence of venting well, } \mathrm{m} \\
H & =\text { height of the screened well through contamination region, } \mathrm{m}
\end{aligned}
$$




\subsubsection{Initial Conditions}

For the 3D-SVE-L model, the initial conditions for the gas flow equations are $p(x, y, z, 0)$ $=p_{a t m}$; saturation of NAPL $S_{n}(x, y, z, 0)$; saturation of aqueous phase $S_{a}(x, y, z, 0)$ and concentration of contaminant $C(x, y, z, 0)$. The initial conditions for all phases are established by the equilibrium relationship. The initial concentration condition data for the 10 sets of lab experiments are listed in Table 4.

\subsubsection{Boundary Conditions}

Boundary conditions for the governing equations can be specified as either constant (Dirichlet boundary condition: Type I) or specified flux (Neumann boundary condition: Type II). In this section the boundary conditions are illustrated for the mass balance of the phase and transport equations, respectively. For each governing equation, the boundary conditions assigned at the venting well, outside boundaries of the simulated domain of the contaminated site, and at the top and bottom of the reactor are presented.

The pressure boundary conditions of the flowing phase are assigned in the following manner:

- At the venting well: For phase flow equations, when assigning an air flow pressure to a venting or injection well, a Dirichlet condition (Type I) is used. The specific exerted vacuum pressure results in a constant-head Dirichlet boundary condition for the radial pressure in the vicinity of the screened venting well. During the lab-scale SVE operation, the airflow rate is controlled. In this context the corresponding absolute pressure at the venting well is calculated by the Equation 9. 
- At the outside of the contaminated site: The region of the site beyond the radius of influence of a venting well is connected to the atmosphere. Therefore, the boundary conditions are assigned as atmospheric pressure, i.e., Type I specific pressure boundary conditions.

- At the top and bottom ends of the reactor: Both the top and bottom of the reactor are completely impermeable, so they are assigned as no flux, i.e., Type II $\frac{\partial p}{\partial z}=0$.

- The boundary conditions of governing equations of immobile phases at the venting well and ground surface are assigned as no flux: $\frac{\partial S_{n}}{\partial x_{j}}=0, \frac{\partial S_{a}}{\partial x_{j}}=0$.

Boundary conditions outside of the domain have not been affected by contamination, hence, NAPL saturation $S_{n}$ is set equal to zero, and the aqueous phase saturation of soil inside the reactor $S_{a}$ is equal to the initial measured saturation of the aqueous phase without contamination.

The boundary conditions of the concentration of contaminants in the transport equations of the NAPL, aqueous and vapour phases are assigned, as follows:

- At the venting well and the ends of reactor: All boundary conditions of transport equation were assigned as Type II zero dispersive flux boundary conditions at the screened part of the venting well, i.e., $\frac{\partial C}{\partial x_{j}}=0$. The non-screened interval of well casing is impermeable and is represented by a Type II no flow boundary condition for flow, and zero concentration and saturation are assigned for transport equations (Nobre and Nobre, 2004).

- At the outside of the contaminated site: Because the region beyond the influence zone of the remediated site is considered as an uncontaminated zone, the boundary condition 
outside of the contaminated zone is assigned Type I, which is zero concentration. All the boundary conditions for the 3D-SVE-L model are illustrated in Figure 1. Figure 2 shows a computational mesh for the SVE-L model.

\subsubsection{The Input Parameters of the 3D-SVE-L model}

Obtaining the numerical solutions of the 3D-SVE-L model requires many input parameters. Inputs include properties of the contaminated soil, empirical parameters, and the physical and chemical properties of toluene. The input parameters for the 3D-SVE-L model are given in Table 3.

\subsubsection{Numerical Solution}

A solution was obtained by changing the NAPL to air mass transfer coefficients "a" and "b" given in Equation 6. The initial values were based on the results of Gidda [2003]. By changing the mass transfer coefficients, a breakthrough curve was generated which was visually compared to the experimental data on a semi-log coordinate system. Once the visual calibration was completed, Equation 10 was used to fine-tune the fit. Mass balances were checked to ensure that a unique solution was obtained. When the minimum NSSRD (normalized sum of the squared relative deviations) value was reached, the best fit was obtained:

$$
N S S R D=\frac{1}{N} \sum_{1}^{N}\left\{\frac{\log \left(C_{g, i}\right)_{\exp }-\log \left(C_{g, i}\right)_{\bmod }}{\log \left(C_{g, i}\right)_{\text {exp }}}\right\}^{2}
$$

\subsubsection{Sensitivity Analysis}


During modeling, it is important to determine which parameter had the largest impact on model output. The common practice is to check each variable one by one within a selected range of lower and upper values [Batu, 2006]. Unfortunately, this does not address the interaction and interactive mechanism of the independent elements at play in SVE.

Multivariable regression analyses can be used to establish the relationship among the different variables in a transport and flow model [Fanchi, 2001]. Comparing to the conventional sensitivity analysis, the multivariable regression sensitivity analysis method can evaluate the uncertainty of the multiple controlling parameters simultaneously. One of the major advantages of this method is a reduction of a random error, which can reduce the residual variance and generates more precise confidence intervals, and helps eliminate bias among variables [Wonnacott andWonnacott, 1981].

In this study, MATLAB [2006] was used to perform the multivariable regression sensitivity analysis. The sensitivity analysis of the calibrated models was done using a $95 \%$ confidence interval.

\subsubsection{Calibration of 3D-SVE Lab Scale Model}

In the SVE lab experiment, five different flow rates were applied to each of the two different soil types. These have been denoted as Cases 1 through 5 for the Elora silt and Cases 6 through 10 for the Ottawa sand. Table 5 gives the resulting parameter values "a" and "b" used for Cases 1 through 10. Table 5 also shows the results of the calibrated 3D-SVE model for each of the 10 cases; that is the resulting $k_{n g}$ and $k_{a g}$ values.

Preliminary modeling showed that the mass transfer coefficient $\left(\mathrm{k}_{\mathrm{ng}}\right)$ from the NAPL to vapour had the biggest impact on the results. The breakthrough curves shown in Figures 3 and 4 
are typical trends for the cases modeled, which is indicative of a non-equilibrium model. Basically fitting parameter " $b$ " tends to dominate the tailing feature of the breakthrough curve and was seen to be sensitive to minor changes as shown in Figure 3. Parameter "a" greatly controls the early stage behaviour of the model, which is consistent with higher initial offgas concentrations due to an increased rate of mass transfer as shown in Figure 4.

Multivariable regression sensitivity analysis of the 3D-SVE lab model by Zhao [2007] showed that the mass transfer coefficient parameter "a" from NAPL to vapour was the most sensitive parameter along with " $b$ ". Sensitivity analysis showed that the next two significant parameters were dispersivity and relative permeability, supporting the decision to make coefficients "c" and "d" constants as suggested by Gidda et al. [2011]. Sensitivity also supported the decision to keep mass transfer coefficients from the aqueous to solid phase, from vapour to solid phase, and from NAPL to aqueous phase as constant values.

Figures $5(\mathrm{a} \& \mathrm{~b})$ and $6(\mathrm{a} \& \mathrm{~b})$ show the reduction in contaminant concentration and the saturation of NAPL after 60 hours from beginning of the simulation for the Elora silt (Case 2). Consequently, the increasing contaminant concentration in the aqueous phase after 60 hours is shown in Fig. 7(a \& b). Breakthrough results are presented in Figure 8 (Case 2) and Figure 9 (Case 4) for Elora silt loam, and Figure 10 for Ottawa sand (case 9). Figure 11 also shows a reduction in toluene concentration in the soil vapour phase versus time for Case 4 . All these figures show that the 3D-SVE model can successfully predict various results from the lab-scale SVE experiments. It is also important that the model is able to represent the three characteristic SVE stages: early sharp decrease of concentrations, transition stage and tailing stage.

Review and analysis of Table 5 shows that regular interdependent relationships do not exist between the soil types, venting flow rates, and the resultant mass transfer empirical 
parameters. The value of "a" varied from 18.5 to $59.2 \mathrm{~h}^{-1}$ for Elora Silt soil, and 4.5 to $43.1 \mathrm{~h}^{-1}$ for Ottawa Sand, which is expected in the general sense as there should be less mass transfer resistance for the Ottawa Sand. Overall the value of "b" was fairly consistent, averaging $1.8 \mathrm{~h}^{-1}$, with a standard deviation of $0.09 \mathrm{~h}^{-1}$. The corresponding initial range of mass transfer coefficients $\left(k_{n g}\right)$ from the NAPL to vapour phase is $4.5 \mathrm{~h}^{-1}$ to $59.2 \mathrm{~h}^{-1}$. This range is consistent with the behaviour of the breakthrough curve at the start of SVE operation. The mass transfer coefficients at the tailing stage of SVE operation were found to be less than 1, except in Case 8 where the tailing effect was not as distinct as compared to the other cases. The wide range of mass transfer coefficients is indicative of the typical non-equilibrium behaviours in both lab and field studies.

The mass transfer coefficients $\left(k_{a g}\right)$ from the aqueous to vapour phase were found to be in the range of $10^{-4} \mathrm{~h}^{-1}$ at the initial stage and in the range of $10^{-6} \mathrm{~h}^{-1}$ at the tailing stage of SVE operation. Previous studies have not distinguished between initial and final mass transfer coefficients and have determined that the "averaged" mass transfer coefficients range between $4 \times 10^{-3} \mathrm{~h}^{-1}$ and $540 \mathrm{~h}^{-1}$ [Rathfelder et al., 2000; Poulson et al., 1996]. Since there is a large difference in between the initial and final mass transfer coefficients, using a single "averaged" mass transfer value is obviously a poor representation of the entire SVE operation. Accordingly, as demonstrated by this study, computing a transient mass transfer coefficient is essential for adequately demonstrating SVE tailing effects.

\subsection{3-D Field Scale Model}

In this section, the general three-dimensional mathematical model is applied to an actual field SVE operation conducted by Conestoga-Rovers and Associates (CRA) [1997]. The system 
configuration including geological data of the site and layouts of monitoring, venting, passive and inject wells have only been described only in a simplified manner. In addition, the modeling domain, initial and boundary conditions, calibration and the outputs of the simulated variables are demonstrated. The effects of operation conditions on the concentration of off gas are examined by calibrating of 3D-SVE-F model and determining the governing mass transfer coefficients.

A contaminated gasoline station being remediated by CRA [1997] was used for the field scale site conditions. The site was paved entirely with several pump islands and a building. The soil on site consisted of silty sand soil, with both water and soil contamination. The TPH levels in the soil varied from 100 to $1920 \mu \mathrm{g} / \mathrm{g}$, while the water had TPH levels varying from 4 to 52 mg/L. CRA also monitored Benzene, Toluene, Ethylbenzene and Xylene (BTEX) concentrations. For this study, the majority of analysis was done with the TPH levels.

For the study site, CRA installed more than 20 monitoring wells to gather subsurface information. The concentration of contaminants in the soil, groundwater, soil vapour were monitored over time at the different monitoring wells. In order to make the modelling manageable, a sub-region of the study site was selected, with the sub-region having the dimensions of $10 \mathrm{~m}$ length by $10 \mathrm{~m}$ width by $5 \mathrm{~m}$ depth. The soil domain consisted of isotropic and homogeneous silty sand. The radius of influence for a single well in the sub-region was approximately $5 \mathrm{~m}$ as shown in Figure 12. The data from the single venting well was used to develop the 3D-SVE-F model and implement calibration against the sampled off gas concentrations.

The corresponding conceptual model for this SVE remediation operation was proposed as follows. A screened venting well was controlled by a blower set to a specific vacuum pressure. The vacuum causes air to flow radially through the contaminated silty sand zone towards the 
venting well, carrying the vapour with it. During SVE operation, the residual contaminant BTEX mixture was removed by advection and dispersion transport in the vapour phase with rate-limited mass transfer between contiguous phases. The contaminated vapour was then carried away from the subsurface up to ground surface where the vapour was treated. Non-equilibrium mass transfer was considered between NAPL to vapour phase, NAPL to aqueous phase, aqueous to vapour phase, and aqueous to solid phase.

\subsubsection{Boundary and Initial Conditions}

The fundamental principles for the flow and transport equation are similar to the initial and boundary conditions introduced for the lab-scale model. The initial conditions are given in the Table 7. The following three types of boundaries have been assigned:

- boundary conditions at the outside of the simulated contaminated zone, which are via natural leakage to the atmosphere

- boundary conditions at a venting well, where the controlled vacuum pressure is induced

- boundary conditions at the ground surface and the bottom of the site

There are two alternatives on handling the ground surface of the site. The vapour phase boundaries on the surface may be in the range from completely impermeable to vapour transport (e.g., when the ground is covered) or to very permeable (e.g., when the ground is uncovered, open to the air). If open to air, i.e., uncovered, the ground surface of the site is connected to the atmosphere, allowing use of a Type I boundary condition, where the pressure at the ground surface is equal to atmospheric pressure. If the covered surface exists, the surface boundary

condition is assigned as no-flow boundary condition, i.e., Type II $\frac{\partial p}{\partial x_{j}}=0, x_{j}$ refers to $x, y, z$ 
coordinate directions. The bottom soil zone is assumed to be impermeable; hence it is treated the same as a covered surface, i.e., no-flow boundary condition $\frac{\partial p}{\partial z}=0$.

Boundary conditions of immobile phase mass balance equations at the venting well and the ground surface are assigned as no flux, that is, $\frac{\partial S_{n}}{\partial x_{j}}=0, \frac{\partial S_{a}}{\partial x_{j}}=0$. Boundary conditions at the outside of the domain have not been affected by contamination, hence, NAPL saturation $S_{n}$ is equal to zero, and the aqueous phase saturation of soil porous media $S_{a}$ is equal to the initial measured saturation of the aqueous phase in soil without contamination.

In the transport equations, for the individual component $k$ in phase $\beta$, the outside boundary conditions of the domain are assigned as specific concentration of zero, $C_{\beta, k}=0$. Other boundary conditions are considered as zero flux, $\frac{\partial C_{\beta, k}}{\partial x_{j}}=0,\left(x_{j}\right.$ refers to $\left.x, y, z\right)$. The details on the assigned boundary conditions are illustrated in Figure 13.

\subsubsection{The Inputs for the 3D-SVE-F Model}

Generally, there are two different groups of considered parameters, which are site/contaminant parameters and SVE operation design parameters [Nobre and Nobre, 2004]:

- data from the field SVE operation, such as site borehole sampling data, site historical data, properties of the contaminated soil, and other measurable data

- empirical parameters, data on physical and chemical properties of BTEX from literature. The chemical properties of BTEX are given in Table 6 and input parameters of SVE-F model are given in Table 7. 


\subsubsection{Calibration of the 3D-SVE Field Scale Model}

The supporting data for the 3D-SVE field scale model was taken from CRA's operational data set for the field site and are given in Table 7. For simplicity reasons, the only output values examined during the calibration phase were TPH levels.

In order to determine whether the lab mass transfer coefficients could be transferred to the field scenarios, the determined mass transfer coefficients from the lab case were tried in the field model. The results showed that the 3D field-scale case was not well represented as shown in Figure 14. This suggests the presence of scale-up factors when transferring results from the lab to the field scenario. Another possible cause for the difference in values was that the site was modeled as homogenous, while in fact it was heterogeneous. The changes in permeability that go with a heterogeneous site can affect advection-dispersion transport. For example, contaminant distributed in the lower permeability zones will not be removed easily and will exhibit mass transfer limitations due to lower seepage velocity. Contamination transport in the low permeability zones will also be affected by diffusion, contributing to tailing effects. That is why when the SVE systems are temporarily shutdown, the gas concentrations rebound when the system is turned back on. Accordingly, lab studies of a more complicated nature are needed to study the effects of heterogeneity and allow evaluation of scale-up factors so that lab data can be transferred to the field

The next step was to calibrate the field data using the same procedure as used for the labscale model, with "a" and " $b$ " being the fitting parameters and keeping the other coefficients as constants. Consideration was also given to making "c" and " $\mathrm{d}$ " fitting parameters due to the higher water content in the field with respect to the lab scenario. To determine whether "c" and " $d$ " played a bigger role in the model due to the presence of water in the soil, a few predictions 
were made with "c" and "d" as variables. The fitting results did not improve. This was further confirmed by the multivariable regression, which showed that $\mathrm{k}_{\mathrm{ag}}$ was not a sensitive variable in model predictions. Therefore, similar to the lab model, the field model had constant "c" and "d" values. However, the sensitivity analysis confirmed that the mass transfer coefficient from NAPL to vapour phase was the most sensitive parameter with value "a" and having the highest impact. This was followed by permeability and then dispersivity. Therefore, the field-scale and lab-scale models were found to differ by the parameters that were most sensitive, (i.e., "a" or "b"), and by the impact of permeability and dispersivity. This difference makes sense and can be attributed to the mass transfer limitations taking place in the field, which were simplified and modeled as a homogenous situation.

However, the impact of the two mass transfer empirical parameters "a" and "b" on the 3D-SVE field model is similar to those found for the lab-scale model. Parameter "a" affects the concentration of effluent gas along the entire life of the SVE operation, but most markedly in the early stages. Parameter "b" has the biggest impact on the tailing stage of the breakthrough curve.

An additional challenge in fitting the field data is the three possible breakthrough curves as seen in Figure 14. The three different tendencies were present due to variations in real data provided by CRA. These three tendencies can be described as top (early-time), middle (medtime) and bottom (tailing). The reason for the jump/variations in the real data is not known, but may be related to operational challenges. Unfortunately, details of operational challenges that caused jumps in the off gas levels were not contained in the data forwarded by CRA.

The empirical parameters corresponding to the best fit for these three possible tendencies are summarized in Table 8. The mass transfer coefficients for the NAPL to vapour phase are on 
the order of $10^{-4} \mathrm{~h}^{-1}$ for the initial stage of SVE operation, and around $10^{-6} \mathrm{~h}^{-1}$ at the tailing stage. The mass transfer coefficient for the aqueous to vapour phase varied from $10^{-6} \mathrm{~h}^{-1}$ to $10^{-9} \mathrm{~h}^{-1}$.

Comparing the calibrated field coefficients to the lab coefficients shows some significant differences. The value of "a" in the field model were approximately 5 orders of magnitude smaller than in the lab model, while the value of "b" essentially kept the same. This shows that even though the lab values cannot be used to simulate the field situation, the field values are consistent with an environment that has more resistance in the NAPL to vapour gas transfer. Similarly, the aqueous to vapour mass transfer coefficient in the field is 2 to 3 orders of magnitude smaller. This increased resistance is consistent with the increased water content present in the field, even though the sensitivity analysis shows that aqueous to vapour mass transfer is not highly significant. The values of mass transfer coefficient from aqueous to solid phase, and from NAPL to aqueous phase were identical in both situations. Overall, the comparison of mass transfer coefficients between lab and field has shown that the field conditions are more resistant to mass transfer, consistent with high water content, more complex soil properties, and site heterogeneity. This is consistent with the findings of McCray et al. [2011].

The mass transfer trend noticed in this study is consistent with that of Saenton and Illangasekare [2007], who reported that field mass transfer coefficients were lower than laboratory determined values for a groundwater scenario. As noted earlier, some of the difference between field and lab values can be attributed to both scenarios being modelled as homogeneous. Accordingly, more research is needed to refine the difference between lab and field mass transfer coefficients so that the scale-up factor can be determined. Analysis of additional field case studies would be beneficial [McCray et al., 2011]. This will assist with field 
predictions and determining if SVE is the appropriate treatment technology. Based on the dearth of mass transfer coefficients values in the literature, and majority of SVE sites having permeable soils, the use of the mass transfer coefficients values identified in the paper should be limited to permeable soils.

\section{3D-SVE Field Scale Model in a Heterogeneous Domain}

Currently, little modeling effort on tailing effects has been reported in research literature, particularly with three-dimensional medium heterogeneities and non-equilibrium mass transfer. Exploring the implications of non-equilibrium interphase mass transfer of three-dimensional models requires the analysis of the effluent gas concentration from the field-scale investigation with significant heterogeneity in relative permeability. Given this need, this section is used to demonstrate the ability of applying the 3D-SVE-F model to a heterogeneous domain to study the impact of porous medium heterogeneity on the long tailing effect.

For heterogeneous soil, air permeability can vary greatly over the entire site in the range of 100- to 10,000-fold, depending on the soil types [Baehr and Hult, 1991]. An ideal three-layer soil porous medium is hypothetically simulated to investigate the impacts of the heterogeneous permeability as shown in Figure 15. The permeability with the top layer and bottom layers is equal to $3 \times 10^{-12} \mathrm{~m}$, which is the same as the SVE-F homogeneous domain. The middle layer has a permeability 100 times higher than top and bottom layers, i.e., $3 \times 10^{-10} \mathrm{~m}$. All other inputs are the same as those used in the previously 3D-SVE-F scenario. The SVE model for this heterogeneous domain is entitled 3D-SVE-FH model.

The distribution of benzene contaminant in three layers in the vicinity of the venting well at the beginning $(\mathrm{t}=0)$ and at 300 days is shown in Figure 16 (a \& b), respectively. The apparent 
higher concentration of contaminants in soil vapour phase is in the region where the permeability is lower. Figure 17 shows the distribution of the concentration of benzene in soil vapour phase versus time along the line connected from two point coordinates $(5,5.5,0)$ and $(5,5.5,5)$ in the simulated domain and $0.5 \mathrm{~m}$ away from the venting well, parallel to the venting well. During a certain elapsed time, the simulated results show that benzene in the soil vapour phase is distributed mainly in the low permeability zone at the tailing stage. This indicates that the contaminants in soil vapour phase in the higher permeability vadose zone have been easily removed by advection-dispersion transport with higher seepage velocity and rate of mass transfer. However, the contaminants distributed in the lower permeability vadose zone still remain in the soil vapour phase due to the lower seepage velocity. The contaminants in the low permeability zone further diffuse into the adjacent layers, contributing to tailing effects. If the venting well is shut down, and then reopened, the concentration of off gas will rebound because of diffusion. This result implies the importance with respect to exploring the variations in permeability over the soil site and conducting a thorough site investigation before SVE operations.

\section{CONCLUSIONS}

The developed 3D SVE-L/F numerical model incorporated multiphase flow, multicomponent transport and non-equilibrium transient mass transfer. The numerical model has been intensively calibrated against the experimental data from our lab-scale reactor experiment, and also against the field data conducted by Conestoga Rovers and Associates (CRA, 1997). Finally, a demonstrated simulation for a hypothetical heterogeneous field site to study the impact of porous medium heterogeneity on the long tailing effect was implemented. 
Calibration of the model showed that 3D-SVE can predict laboratory findings and allows for changes in the important governing mass transfer relationships. The laboratory simulations showed that it is important to compute transient mass transfer coefficients in order to understand SVE tailing effects. Furthermore, a single "averaged" mass transfer value is a poor representation of the entire SVE operation. The mass transfer coefficient from NAPL to vapour phase was the most significant, as was confirmed by the multivariable sensitivity analysis. The results show that the model can be used to predict spatial and temporal progress of the SVE operation and provide a true representation of the tailing stages.

However, comparison between the lab and field scale predictions showed that the mass transfer coefficients for the lab could not easily be transferred to the field model. This suggests the presence of a scale-up factor, with the field mass transfer coefficients being smaller than the lab scale mass transfer coefficients. For both the lab and field scenarios, NAPL to air was the dominant mass transfer relationship, while the mass transfer coefficient values for aqueous to solid phase, and NAPL to aqueous phase being identical in both scenarios. Since the field case was modeled as a homogenous site, further studies need to be completed to determine the magnitude of the scale-up factor. Further research is required for the scale-up factors with more complex lab studies that account for water content, more complex soil properties and site heterogeneity. Determining these scale-up factors is important when utilizing a 3D-SVE model based on lab setting results to design a SVE system that includes the optimization of well placement locations, well venting rates, and predicting the required cleanup time. 


\section{ACKNOWLEDGEMENTS}

The authors gratefully acknowledge the financial support provided by the NSERC Strategic Grant Program. Appreciation is also extended to Conestoga Rovers and Associates, the industrial partner for the project, for their SVE insights and technical data from a SVE field operation.

\section{REFERENCES}

Abriola, L., Lang, M., and Rathfelder, J. K. (1997). Michigan soil vapor extraction remediation (MISER) model-A computer program to modeling bioventing of organic chemicals in unsaturated geological material, USEPA, Cincinnati, Ohio, EPA/600/SR-097/099.

Abriola, L.M., Pennell, K.D., Weber, W.J., Lang, J.R. and Wilkins, M.D. (1999) Persistence and interphase mass transfer of liquid organic contaminants in the unsaturated zone, Experimental Observations and Mathematical Modeling, published in Vadose Zone Hydrology: Cutting Across Disciplines, Oxford University Press, ISBN: 0-19-510990-2.

Baehr, A.L., and Hult, M.F. (1991) Evaluation of unsaturated zone air permeability through pneumatic tests, Water Resources Research, 27(10):2605-2617.

Barnes, D. L. and White, T.C (2006) Application of a Simple Decision Model for Soil Vapor Extraction System Operation, Ground Water Monitoring and Remediation, 26(4):107-114.

Barnes, D.L. (2003) Estimation of operation time for soil vapor extraction systems, Journal of Environmental Engineering, 129(9):873-878

Batu, V. (2006) Applied flow and solute transport modeling in aquifers fundamental principled and analytical and numerical methods, CRC - Taylor \& Francis Group, Boca Raton, FL.

Bear, J. (1972) Dynamics of fluids in porous media, New York: American Elsevier.

Benson, D. A. (2011) VENT2D \& VENT3D Finite-difference models of multi-compound vapor transport and phase distribution, http://inside.mines.edu/ dbenson/vent/v2dbroch.html, Nov.

Bradner, G.C. and Murdoch, L.C. (2005) Effects of skin and hydraulic fractures on SVE well, Journal of Contaminant Hydrology, 77 (3): 271-297.

Brusseau, M.L., Rohay, V. And Truex, M.J. (2010) Analysis of Soil Vapor Extraction Data to Evaluate Mass-Transfer Constraints and Estimate Source-Zone Mass Flux. Ground Water Monitoring \& Remediation, 30(3):57-64.

Carroll, K.C., Oostrom, M., Truex, M.J., Rohay, V.J. and Brusseau, M.L. (2012) Assessing performance and closure for soil vapor extraction: Integrating vapor discharge and impact to groundwater quality. Journal of Contaminant Hydrology, 128:71-82.

Chai, J. C and Miura, N. (2004) Field vapor extraction test and long-term monitoring at a PCE contaminated site, Journal of Hazardous Materials, 110(1-3):85-92.

COMSOL Inc. (2006) Comsol Multiphysics ${ }^{\circledR}$, Burlington, MA.

CRA (1997) Conestoga Rovers and Associates, Waterloo, ON N2V 1C2, Canada 
Duggal, A. and Zytner, R.G. (2009) Scale up factors for Large Scale SVE, Environmental Technology, 30(4):407-409.

Fanchi, J.R. (2001) Principles of applied reservoir simulation, 2nd Edition, Gulf Professional, Elsevier, St. Louis, MO.

Gidda, T. (2003) Mass transfer process in the soil vapor extraction of gasoline from unsaturated soils, $\mathrm{Ph}$. D thesis, University of Guelph.

Gidda, T., Cann, D., Stiver, W.H. and Zytner, R.G. (2006) Airflow dispersion in unsaturated soil, $\mathrm{JCH}, 82: 118-132$.

Gidda, T., Stiver, W.H. and Zytner, R.G. (2011) Measuring Aqueous-Air and Sorbed -Aqueous Mass Transfer Coefficients for Application in Soil Vapour Extraction, Journal of Environmental Engineering, doi:10.1061/(ASCE)EE. 1943-7870.0000405

Harper, B.M., Stiver, W.H. and Zytner, R.G. (2003) Nonequilibrium Nonaqueous Phase Liquid Mass Transfer Model for Soil Vapour Extraction Systems, Journal of Environmental Engineering, 129(8): 745-754.

Høier, C.K., Sonnenborg, T.O., Jensen, K.H. and Gudbjerg, J. (2009) Model Analysis of Mechanisms Controlling Pneumatic Soil Vapor Extraction. Journal of Contaminant Hydrology, 103:82-98.

Johnson, P. C., Stanley, C.C., Kemblowski, M.W., Byers, D.L. and Colthart, J.D. (1990) A practical approach to the design, operation and monitoring of in situ soil-venting systems, Groundwater Monitoring Review, 10(2): 159-78.

Lenhard, R.J. and Parker, J.C. (1987) A model for hysteretic constitutive relations governing multiphase flow: 2. Permeability-saturation relations. Water Resources Research, 23(11): 2197-2206.

Lingineni, S. and Dhir, V.K. (1997) Controlling transport processes during NAPL removal by soil venting. Advances in Water Resources, 20(2-3):157-169.

Looney, B.B. and Falta, R.W. (2000) Vadose zone science and technology solutions, Battelle Press, ISBN: 1-57477-085-3.

MATLAB (2006) The MathWorks Inc., Natick, MA, http://www.mathworks.com/

McCray, J.E., Tick, G.R., Jawitz, J.W., Gierke, J.S., Brusseau, M.L., Falta, R.W., Knox, R.C., Sabatini, D.A., Annable, M.D., Harwell, J.H. and Wood, A.L. (2011) Remediation of NAPL Source Zones: Lessons Learned from Field Studies at Hill and Dover AFB, Ground Water, 49(5):727-744.

Miller, C. T., Christakos, G., Imhoff, P. T., McBride, J. F., Pedit, J. A . and Trangenstein, J. A., (1998) Multiphase flow and transport modeling in heterogeneous porous media: challenges and approaches, Advances in Water Resources, 21(2): 77-120.

Nobre, M. and R. C. M. Nobre, 2004. Soil vapour extraction of chlorinated solvent in industrial site in Brazil, Journal of Hazardous Materials, 110(1): 119-127.

Poulsen, T.G., Massmann, J.W. and Moldrup, P. (1996) Effects of vapour extraction on contaminant flux to atmosphere and ground water, Journal of Environmental Engineering, 122(7): 700-706.

Rahbeh, M.E. and Mohtar, R.H. (2007) Application of multiphase transport models to field remediation by air sparging and soil vapour extraction, J. Hazardous Materials, 143:156170.

Rathfelder, K.M., Lang, J.R and Abriola, L.M. (2000) A numerical model (MISER) for the stimulation of coupled physical, chemical and biological processes in soil vapor extraction and bioventing system, Journal of Contaminant Hydrology, 43(3-4): 239-270. 
Saenton, S. and Illangasekare, T.H. (2007) Upscaling of mass transfer rate coefficient for the numerical simulation of dense nonaqueous phase liquid dissolution in heterogeneous aquifers, Water Resources Research, 43, doi:10.1029/2005WR004274

Schwartz, F.W and Zhang, H. (2003) Fundamentals of ground water, John Wiley \& Sons, INC., ISBN: 0-471-13785-5.

Scientific Software Group (2011) SVE-3D Modelling, http://www.scientificsoftwaregroup.com, November.

Sleep, B. E. and Sykes, J.F. (1989) Modeling the transport of volatile organics in variably saturated media, Water Resources Research, 25(1): 81-92.

Sleep, B.E., and Sykes, J.F. (1993) Compositional simulation of groundwater contamination by organic compounds, 1. Model development and verification, Water Resources Research, 29(6):1697-708.

Thomson, N.R., Sykes, J.F. and Vliet, D.V. (1997) A numerical investigation into factors affecting gas and aqueous phase plumes in the subsurface, Journal of Contaminant Hydrology, 28(1-2): 39-70.

USACE (2002) US Army Corps of Engineers Engineering and Design: Soil Vapor Extraction and Bioventing. EM 1110-1-4001.

Van Dijke, M.I.J., van Duijn, C.J. and van der Zee, A.T.M. (1995) Multiphase flow modeling of air sparging, Adv. Water Res. 18 (3) 319-333.

Van Genuchten, M. T. (1980) A closed-form equation for predicting the hydraulic conductivity of unsaturated soils, Soil Science society American Journal, 44(8): 892-898.

Wonnacott, T.H. and Wonnacott, R.J. (1981) Regression: A second course in Statistics, John Wiley \& Sons, ISBN:0-471-95974-X.

Yoon, H., Kim, J.H., Liljestrand, H.M., and Khim, J. (2002) Effect of water content on transient non-equilibrium NAPL-gas mass transfer during soil vapour extraction. $J$. Contaminant Hydrology, 54:1-18.

Zhao, L. (2007) Three-dimensional SVE modeling, PhD thesis, University of Guelph, Guelph, ON.

Zhao, L. and Zytner, R.G. (2008) Estimation of SVE Closure Time, J. Hazardous Materials, 153:575-581.

Zou, S. and Parr, A. (1993) Estimation of dispersion parameters for two dimensional plumes, Ground Water, 31:389-392. 


\section{Table Captions}

Table 1: Comprehensive Comparison of 3D Models

Table 2: Summary of Mass Transfer Coefficients Applied in the 3D-SVE Model

Table 3: Soil Properties and Inputs for Numerical Simulation 3D-SVE-L Model

Table 4: Initial Conditions of Lab Experiment

Table 5: Lab Conditions Tested and Mass Transfer Coefficients for Lab Scale SVE

Table 6: Properties of BTEX

Table 7: Inputs for Numerical Simulations of the 3D-SVE Field Scale Model

Table 8: Determined Mass Transfer Coefficients for the 3D-SVE Field Model

Figure Captions

Figure 1: A schematic of boundary conditions for the 3D-SVE-L model

Figure 2: Computational mesh

Figure 3: Fitting Results for Parameter " $b$ " Variation

Figure 4: Effect of empirical parameter " $a$ " in the mass transfer coefficient

Figure 5a: Concentration of contaminant at the beginning of the simulation (Case 2)

Figure 5b: Concentration of contaminant after 60 hours (Case 2)

Figure 6a: Saturation of NAPL at the beginning of the simulation (Case 2)

Figure 6b: Saturation of NAPL after 60 hours (Case 2)

Figure 7a: Saturation of water (aqueous) at the beginning of the simulation (Case 2)

Figure 7b: Saturation of water (aqueous) after 60 hours (Case 2)

Figure 8: Best fitting results for Elora Silt (Case 2)

Figure 9: Best fitting results for Elora Silt (Case 4) 
Figure 10: Best fitting results for Ottawa sand Elora Silt (Case 9)

Figure 11: Concentration of Toluene in Soil Vapour Phase versus time for Case 4

Figure 12: Schematic of the Simulated SVE Site Remediated by CRA in 1997

Figure 13: A schematic diagram of boundary conditions for the field case

Figure 14: Matched Results for Field SVE Operation

Figure 15: The Hypothetical Heterogeneous SVE Site

Figure 16a: The Profile of Concentrations Distributed in Different Zones at $\mathrm{t}=0$

Figure 16b: The Profile of Concentrations Distributed in Different Zones at $\mathrm{t}=300 \mathrm{~h}$

Figure 17: Concentration of Benzene in Soil Vapour versus Time along vertical line $0.05 \mathrm{~m}$ radially away from venting well 
Table 1. Comprehensive Comparison of 3D Models

\begin{tabular}{|c|c|c|c|c|}
\hline Models & 3D-SVE-F & SVE-3D & VENT3D & Other models \\
\hline Developer & $\begin{array}{l}\text { Authors of this } \\
\text { paper }\end{array}$ & $\begin{array}{l}\text { Scientific Software } \\
\text { Inc., } 2005\end{array}$ & Benson et al., 1993 & $\begin{array}{l}\text { Sleep and Sykes, } 1989, \\
\text { Abriola et al., } 1997 \\
\text { Rathefelder et al., 2000, } \\
\text { Thomson et al., 1997, }\end{array}$ \\
\hline Numerical scheme & $\begin{array}{l}\text { Finite element } \\
\text { FEMLAB }\end{array}$ & Finite element & Finite difference & $\begin{array}{c}\text { Finite difference or finite } \\
\text { element }\end{array}$ \\
\hline User Adaptation & $\sqrt{ }$ & $\mathrm{X}$ & $\mathrm{X}$ & $\mathrm{X}$ \\
\hline $\begin{array}{l}\text { Heterogeneous } \\
\text { permeability }\end{array}$ & $\sqrt{ }$ & $\sqrt{ }$ & $\sqrt{ }$ & Limited \\
\hline Multicomponent & $\sqrt{ }$ & $\sqrt{ }$ & $\sqrt{ }$ & $\sqrt{ }$ \\
\hline Phases & $\begin{array}{l}4 \text { phases, single gas } \\
\text { active phase flow }\end{array}$ & $\begin{array}{l}4 \text { phases, three } \\
\text { phase flow }\end{array}$ & Gas phase only & Aqueous and gas phase flow \\
\hline Mass Transfer & $\begin{array}{c}\text { Nonequilibrium } \\
\text { Transient mass } \\
\text { transfer coefficients } \\
\end{array}$ & $\begin{array}{l}\text { Nonequilibrium, } \\
\text { constant mass } \\
\text { transfer coefficients }\end{array}$ & Equilibrium & $\begin{array}{c}\text { Nonequlibrium } \\
\text { Constant mass transfer } \\
\text { coefficients } \\
\end{array}$ \\
\hline Special features & $\begin{array}{l}\text { Predict closure time } \\
\text { and degree of final } \\
\text { cleanup }\end{array}$ & $\begin{array}{l}\text { Estimate number of } \\
\text { SVE wells, wells' } \\
\text { spacing, and cleanup } \\
\text { time under complex } \\
\text { conditions }\end{array}$ & $\begin{array}{l}\text { Third-order vapor } \\
\text { transport algorithm }\end{array}$ & Model-dependent \\
\hline $\begin{array}{l}\text { Calibration } \\
\text { Adjustable } \\
\text { parameters }\end{array}$ & $\begin{array}{c}\sqrt{ } \\
\text { Mass transfer } \\
\text { empirical } \\
\text { parameters }\end{array}$ & $\begin{array}{c}\sqrt{ } \\
\text { first order } \\
\text { biodegradation } \\
\text { simulated }\end{array}$ & $\begin{array}{c}\sqrt{ } \\
\text { Initial concentration }\end{array}$ & $\begin{array}{c}\sqrt{ } \\
\text { Intermodel, analytical solution }\end{array}$ \\
\hline
\end{tabular}

Table 2: Summary of Mass Transfer Coefficients Applied in the 3D-SVE Model

\begin{tabular}{c|c|c}
\hline $\begin{array}{c}\text { Nonequilibrium Phase } \\
\text { pairs }\end{array}$ & Expressions or values, $\mathrm{h}^{-1}$ & Remarks \\
\hline NAPL to vapour & $k_{n g}=a\left(\frac{S_{n}}{S_{n, i}}\right)^{b}$ & $\begin{array}{c}\text { "a", "b" are adjustable } \\
\text { parameters }\end{array}$ \\
\hline Aqueous to vapour & $k_{a g}=c\left(C_{a}\right)^{d} c=0.001, d=1.9$ & "c", "d" values are \\
{$\left[k_{a s}=3.6\right.$} & {$[12]$} \\
\hline Aqueous to solid & $k_{n a}=36$ & {$[12]$} \\
\hline NAPL to aqueous &
\end{tabular}


Table 3 Initial Conditions of Lab Experiment

\begin{tabular}{|c|c|c|c|c|c|c|c|c|c|c|}
\hline \multirow{3}{*}{ Case Number } & \multicolumn{10}{|c|}{ SVE Experiments } \\
\hline & \multicolumn{5}{|c|}{ Elora Silt } & \multicolumn{5}{|c|}{ Ottawa Sand } \\
\hline & 1 & 2 & 3 & 4 & 5 & 6 & 7 & 8 & 9 & 10 \\
\hline $\begin{array}{l}\text { Concentration of toluene } \\
\text { in soil gas phase* } \\
\left(\mathrm{mol} / \mathrm{m}^{3}\right)\end{array}$ & 1.408 & 1.007 & 0.804 & 0.446 & 0.417 & 1.213 & 1.211 & 1.206 & 1.105 & 1.401 \\
\hline $\begin{array}{l}\text { Saturation of initial } \\
\text { NAPL* }\end{array}$ & 0.027 & 0.027 & 0.020 & 0.016 & 0.011 & 0.025 & 0.025 & 0.025 & 0.024 & 0.027 \\
\hline $\begin{array}{l}\text { Molar density of toluene } \\
* * *\left(\mathrm{~mol} / \mathrm{m}^{3}\right)\end{array}$ & \multicolumn{10}{|c|}{$9.4085 \times 10^{3}$} \\
\hline $\begin{array}{l}\text { Solubility of toluene**, } \\
\left(\mathrm{mol} / \mathrm{m}^{3}\right)\end{array}$ & \multicolumn{10}{|c|}{5.752} \\
\hline
\end{tabular}

* Duggal's experimental design data (2005)

** Reference (ASTM standard E1739-1995)

*** Calculated by Eq. (1) and air flow rate measured by Duggal's experiment (2005) 
Table 4: Inputs for numerical simulation 3D-SVE-L model

\begin{tabular}{|c|c|c|}
\hline Input parameters & Value & Remarks \\
\hline Intrinsic permeability of Elora silt, $k_{s e}, \mathrm{~m}^{2}$ & $6.05 \mathrm{e}^{-12}$ & {$[32]$} \\
\hline Intrinsic permeability of Ottawa sand, $k_{s e}, \mathrm{~m}^{2}$ & $1.98 \mathrm{e}^{-10}$ & {$[32]$} \\
\hline Elora silt bulk density, $\rho_{b e}, \mathrm{~kg} / \mathrm{m}^{3}$ & 1480 & {$[32]$} \\
\hline Ottawa sand bulk density, $\rho_{b o}, \mathrm{~kg} / \mathrm{m}^{3}$ & 1990 & {$[32]$} \\
\hline Initial Contaminant Conc, $\mathrm{g}_{\text {cont }} / \mathrm{g}_{\mathrm{dry}}$ soil & 0.027 & {$[32]$} \\
\hline Octanol-water partitioning coefficient, $\mathrm{K}_{\mathrm{oc}}, \mathrm{L} / \mathrm{kg}, \log K_{o c}$ & 2.13 & {$[37]$} \\
\hline Vapour pressure, $\mathrm{Pa}$ & 3800 & {$[37]$} \\
\hline Water solubility, $\mathrm{kg} / \mathrm{m}^{3}$ & 0.515 & {$[37]$} \\
\hline Density of toluene, $\rho_{n}, \mathrm{~kg} / \mathrm{m}^{3}$ & 866.9 & {$[37]$} \\
\hline Dimensionless Henry’s law constant & 0.26 & {$[37]$} \\
\hline Porosity of Elora silt, $\varphi_{e}$ & 0.40 & {$[32]$} \\
\hline Porosity of Ottawa sand, $\varphi_{o}$ & 0.53 & {$[32]$} \\
\hline Longitudinal dispersivity, $a_{L}, \mathrm{~m}$ & 0.0037 & Assumed \\
\hline Diffusion coefficient in air, $\mathrm{m}^{2} / \mathrm{sec}$ & $8.5 \mathrm{e}-6$ & {$[37]$} \\
\hline Density of air, $\rho_{\text {air }}, \mathrm{kg} / \mathrm{m}^{3}$ & $1.229 \mathrm{e}-3$ & {$[37]$} \\
\hline Dynamic viscosity of air, $\mu, \mathrm{cp}$ & $1.75 \mathrm{e}-5$ & {$[37]$} \\
\hline Residual soil water saturation, $S_{a}$ & 0.001 & {$[32]$} \\
\hline Number of finite elements & 976 & {$[27]$} \\
\hline Time step, $\Delta \mathrm{t}$, hours & 1 & {$[27]$} \\
\hline
\end{tabular}


Table 5: Mass Transfer Coefficients for Lab Scale SVE

\begin{tabular}{|c|c|c|c|c|c|c|c|c|}
\hline \multirow{3}{*}{ № } & \multirow{3}{*}{ Soil type } & \multirow{3}{*}{$\begin{array}{c}\text { Flow } \\
\text { rate } \\
\text { L/min }\end{array}$} & \multirow{2}{*}{\multicolumn{2}{|c|}{$\begin{array}{c}\text { Mass transfer } \\
\text { Empirical } \\
\text { parameters }\end{array}$}} & \multicolumn{4}{|c|}{ Mass transfer coefficient, hour ${ }^{-1}$} \\
\hline & & & & & \multicolumn{2}{|c|}{$k n g$} & \multicolumn{2}{|c|}{ kag } \\
\hline & & & $\mathbf{a}\left[\mathbf{h}^{-1}\right]$ & b & $\begin{array}{l}\text { Initial } \\
\text { value }\end{array}$ & $\begin{array}{l}\text { Final } \\
\text { value }\end{array}$ & $\begin{array}{l}\text { Initial } \\
\text { value }\end{array}$ & $\begin{array}{l}\text { Final } \\
\text { value }\end{array}$ \\
\hline 1 & Elora silt & 9.70 & 32.32 & 1.70 & 32.32 & 0.148 & $1.2 * 10^{-4}$ & $3.2 * 10^{-6}$ \\
\hline 2 & Elora silt & 33.0 & 18.54 & 1.95 & 18.54 & 0.063 & $1.3 * 10^{-4}$ & $4.1 * 10^{-6}$ \\
\hline 3 & Elora silt & 30.6 & 47.78 & 1.81 & 47.78 & 0.727 & $1.3 * 10^{-4}$ & $3.6 * 10^{-6}$ \\
\hline 4 & Elora silt & 30.3 & 42.89 & 1.90 & 42.89 & 0.076 & $1.0 * 10^{-4}$ & $8 * 10^{-7}$ \\
\hline 5 & Elora Silt & 20.9 & 59.23 & 1.80 & 59.23 & 0.443 & $8.0 * 10^{-5}$ & $1 * 10^{-6}$ \\
\hline 6 & Ottawa sand & 1.5 & 6.11 & 1.95 & 6.11 & 0.016 & $1.3 * 10^{-4}$ & $1.2 * 10^{-6}$ \\
\hline 7 & Ottawa sand & 5.4 & 11.27 & 1.80 & 11.27 & 0.603 & $1.4 * 10^{-4}$ & $2 * 10^{-7}$ \\
\hline 8 & Ottawa sand & 10.6 & 12.01 & 1.80 & 12.01 & 1.50 & $4 * 10^{-5}$ & $6.2 * 10^{-6}$ \\
\hline 9 & Ottawa sand & 20.9 & 4.52 & 1.85 & 4.52 & 0.250 & $10^{*} 10^{-4}$ & $2.1 * 10^{-6}$ \\
\hline 10 & Ottawa sand & 11.1 & 43.09 & 1.70 & 43.09 & 0.107 & $1.4 * 10^{-4}$ & $3.4 * 10^{-6}$ \\
\hline
\end{tabular}

Table 6 Properties of BTEX

\begin{tabular}{c|c|c|c|c}
\hline Properties & Benzene & Toluene & $\begin{array}{c}\text { Ethyl } \\
\text { benzene }\end{array}$ & m-Xylene \\
\hline Water solubility, $\mathrm{kg} / \mathrm{m}^{3}$ & 1.7 & 0.515 & 0.152 & 0.125 \\
\hline Molecular weight, $\mathrm{g} / \mathrm{mol}$ & 78 & 92 & 106 & 106 \\
\hline Diffusion coefficient, $\mathrm{m}^{2} / \mathrm{sec}$ & $8.91 * 10^{-6}$ & $8.5^{*} 10^{-6}$ & $7.6^{*} 10^{-6}$ & $7.2^{*} 10^{-6}$ \\
\hline Liquid density, $\mathrm{kg} / \mathrm{m}^{3}$ & 878.7 & 866.9 & 867.0 & 864.2 \\
\hline $\begin{array}{c}\text { Dimensionless Henry's Law } \\
\text { constant (air/aqueous partition } \\
\text { coefficient) }\end{array}$ & 0.22 & 0.26 & 0.32 & 0.29 \\
\hline $\begin{array}{c}\text { Saturated vapour pressure, Pa } \\
\text { Octane-water partitioning } \\
\text { coefficient, } \log K_{o c}, \mathrm{~L} / \mathrm{kg}\end{array}$ & 12700 & 3800 & 1270 & 880 \\
\hline
\end{tabular}

*ASTM standard E1739-1995 
Table 7: Inputs for Numerical Simulations of the 3D-SVE Field Scale Model

\begin{tabular}{|c|c|c|}
\hline Parameter, symbol, unit & Value & Remarks \\
\hline Water residual saturation (immobile), $\mathrm{S}_{\mathrm{wr}}$ & 0.001 & Assumed \\
\hline Aqueous phase saturation, $\mathrm{S}_{\mathrm{w}}$ & 0.1 & Assumed \\
\hline Molecular weight of air, $\mathrm{M}_{\mathrm{air}}$ & 0.0293 & {$[37]$} \\
\hline Intrinsic Permeability, $\mathrm{k}, \mathrm{m}^{2}$ & $1.2^{*} 10^{-12}$ & {$[33]$} \\
\hline Viscosity of air, $\eta, \mathrm{kg} / \mathrm{ms}$ & $1.75^{*} 10^{-5}$ & {$[37]$} \\
\hline Venting flow rate, scft & 1000 & [33] \\
\hline Longitudinal dispersivity, $\mathrm{a}_{\mathrm{L}, \mathrm{m}}$ & 0.6 & Assumed \\
\hline Organic carbon content, $\mathrm{f}_{\mathrm{oc}}, \%$ & 0.02 & {$[33]$} \\
\hline Porosity, $\varphi$ & 0.517 & [33] \\
\hline NAPL saturation, $\mathrm{S}_{\mathrm{ni}}$ & 0.002 & {$[33]$} \\
\hline Soil bulk density, $\rho_{b}$ & 2160 & {$[33]$} \\
\hline Mass transfer empirical parameter $\mathrm{c}$ & 0.001 & {$[12]$} \\
\hline Mass transfer empirical parameter $\mathrm{d}$ & 2 & {$[12]$} \\
\hline $\begin{array}{l}\text { Aqueous solid phase Mass transfer } \\
\text { coefficient, } \mathrm{k}_{\mathrm{as}}, \mathrm{h}^{-1}\end{array}$ & 3.6 & {$[12]$} \\
\hline $\begin{array}{l}\text { NAPL to aqueous phase mass transfer } \\
\text { coefficient, } \mathrm{k}_{\mathrm{N}, \mathrm{a}}, \mathrm{h}^{-1}\end{array}$ & 0.001 & {$[12]$} \\
\hline Temperature, $\mathrm{C}$ & 23 & {$[33]$} \\
\hline Barometric pressure, $\mathrm{Pa}$ & 101325 & {$[37]$} \\
\hline Surface conditions & covered & {$[33]$} \\
\hline Radius of venting well, $\mathrm{cm}$ & 5 & {$[33]$} \\
\hline Residual Soil water content (mobile), $\mathrm{S}_{a}$ & 0.01 & {$[33]$} \\
\hline
\end{tabular}

Table 8: Determined Mass Transfer Coefficients for the 3D-SVE Field Model

\begin{tabular}{c|c|c|l|l|l|c|}
\hline \multirow{2}{*}{ Status of fitting } & \multicolumn{2}{|c|}{$\begin{array}{c}\text { Empirical } \\
\text { parameter }\end{array}$} & \multicolumn{2}{c|}{$k_{n g}\left[\mathbf{h}^{-1}\right]$} & \multicolumn{2}{c}{$k_{a g}\left[\mathbf{h}^{-1}\right]$} \\
\cline { 2 - 7 } & $\boldsymbol{a}\left[\mathbf{h}^{-1}\right]$ & $\boldsymbol{b}$ & $\begin{array}{l}\text { Initial } \\
\text { value }\end{array}$ & $\begin{array}{c}\text { Final } \\
\text { value }\end{array}$ & $\begin{array}{c}\text { Initial } \\
\text { value }\end{array}$ & $\begin{array}{c}\text { Final } \\
\text { Value }\end{array}$ \\
\hline Tailing & $4.17 \mathrm{e}-4$ & 1.8 & $4.17 \mathrm{e}-4$ & $6.02 \mathrm{e}-6$ & $2.16 \mathrm{e}-6$ & $1.02 \mathrm{e}-9$ \\
\hline Med-time & $3.38 \mathrm{e}-4$ & 1.90 & $3.38 \mathrm{e}-4$ & $7.67 \mathrm{e}-6$ & $2.16 \mathrm{e}-6$ & $2.67 \mathrm{e}-9$ \\
\hline Early time & $3.76 \mathrm{e}-4$ & 1.95 & $3.76 \mathrm{e}-4$ & $9.01 \mathrm{e}-6$ & $2.16 \mathrm{e}-6$ & $9.01 \mathrm{e}-9$ \\
\hline
\end{tabular}




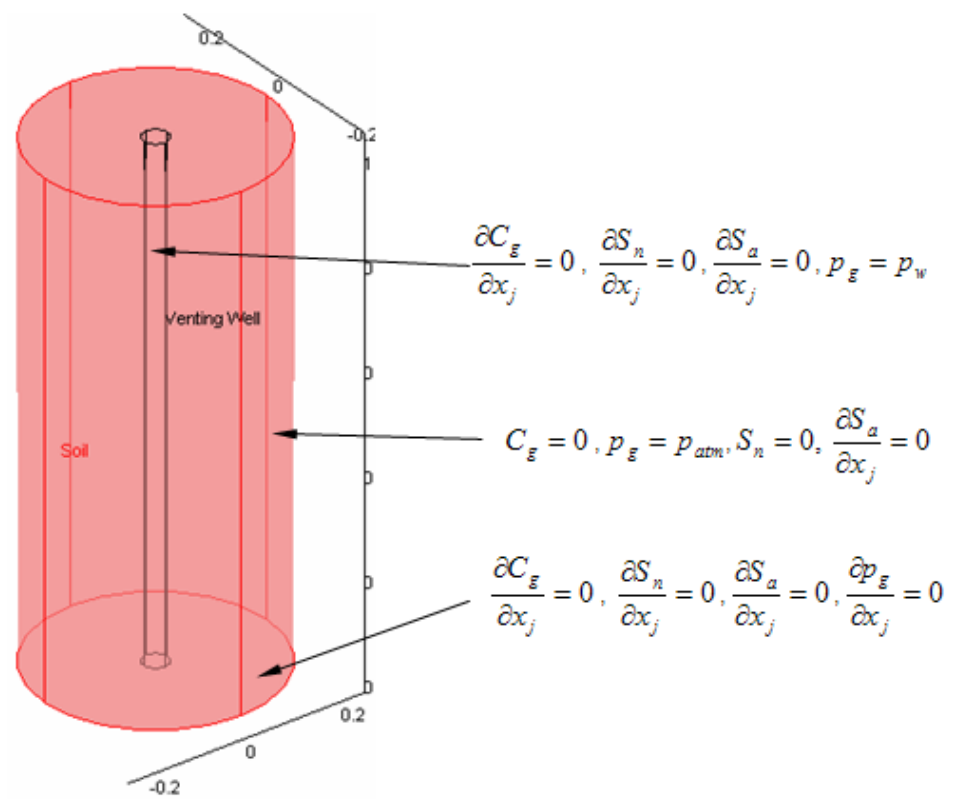

Figure 1: A schematic of boundary conditions for the 3D-SVE-L model 


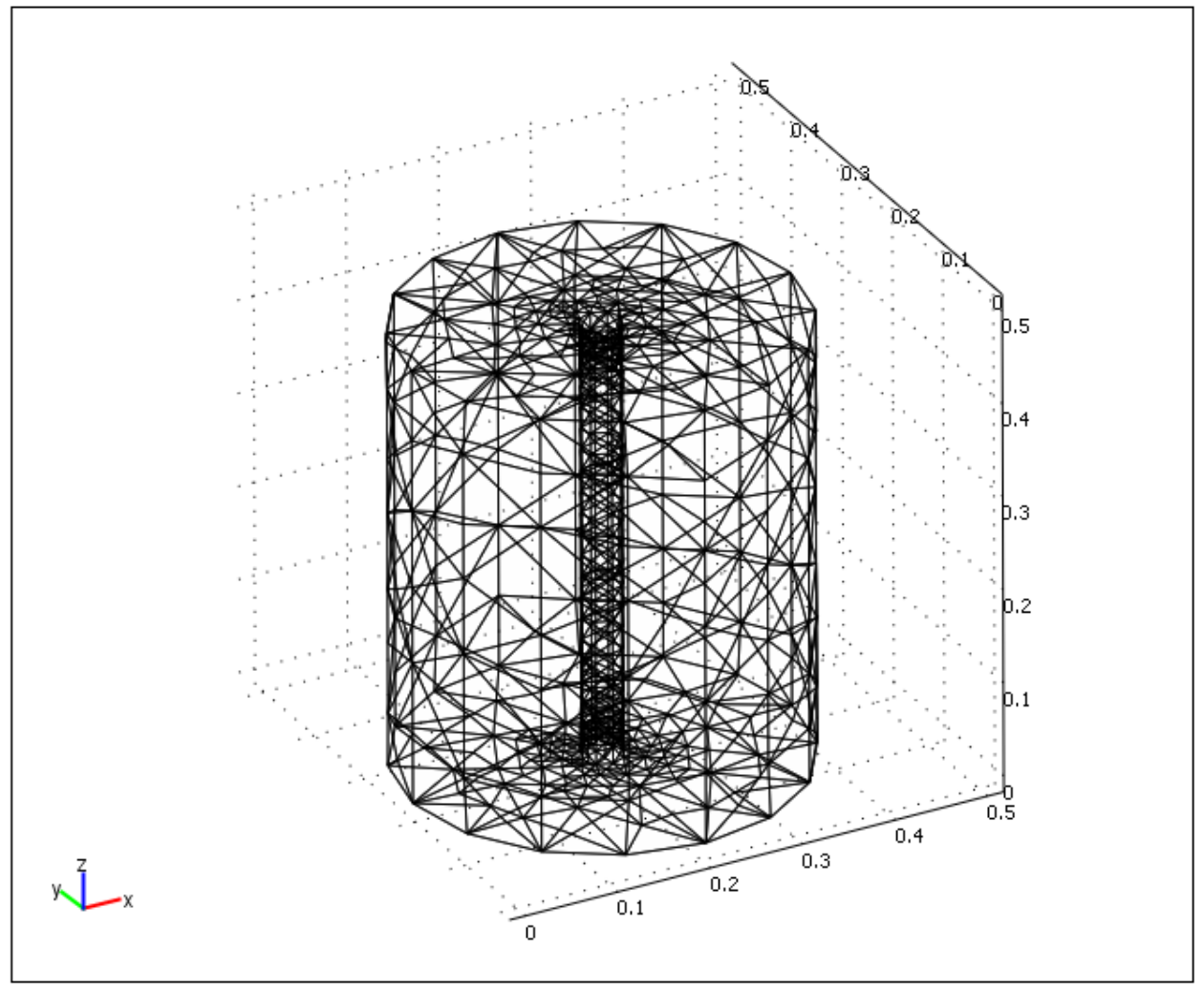

Fig. 2: Computational mesh for the 3D-SVE-L model 


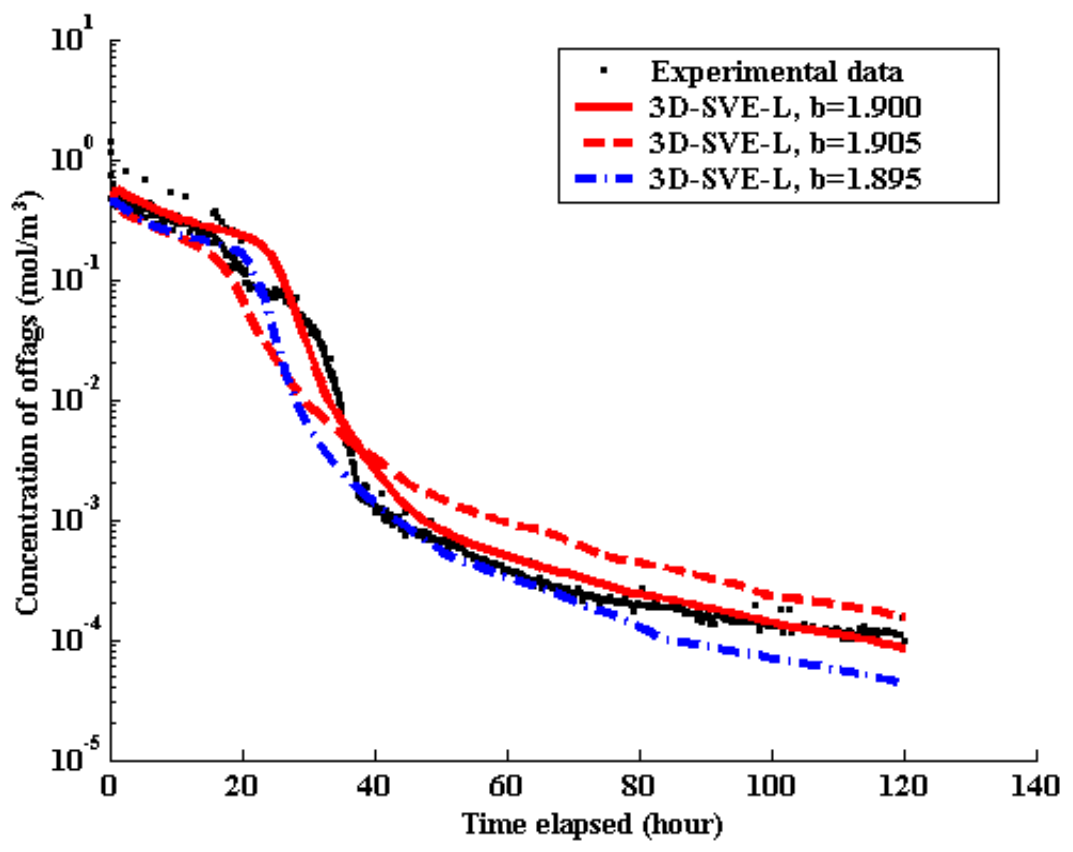

Figure 3: Fitting Results for Parameter " $b$ " Variation 


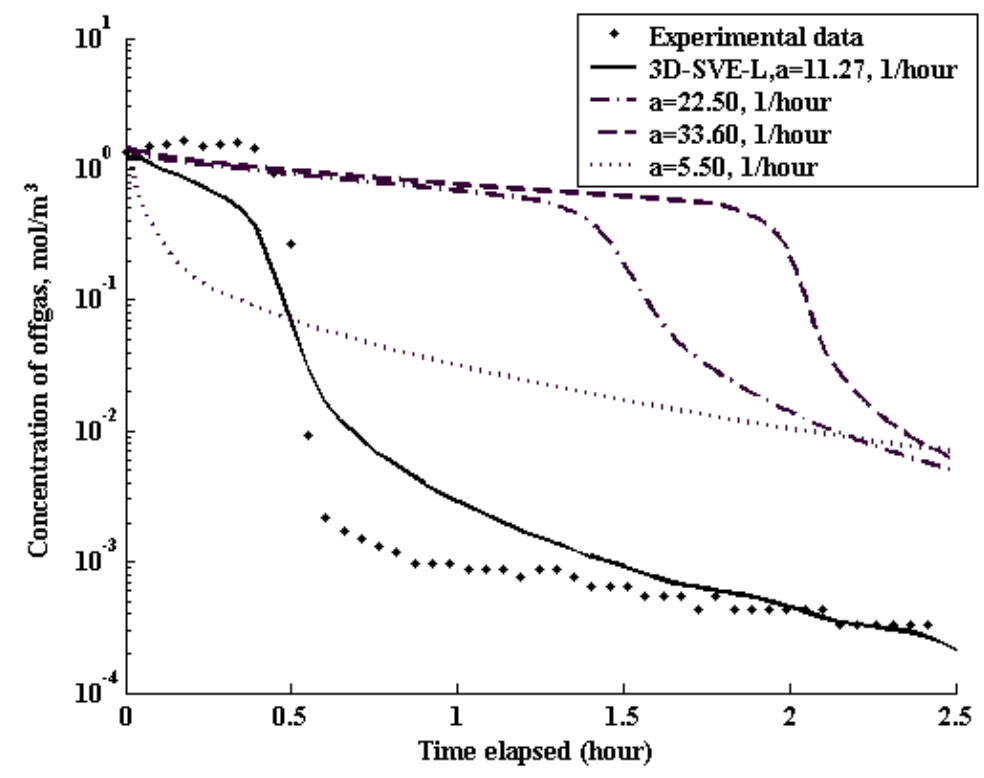

Figure 4: Effect of empirical parameter "a" in the mass transfer coefficient 


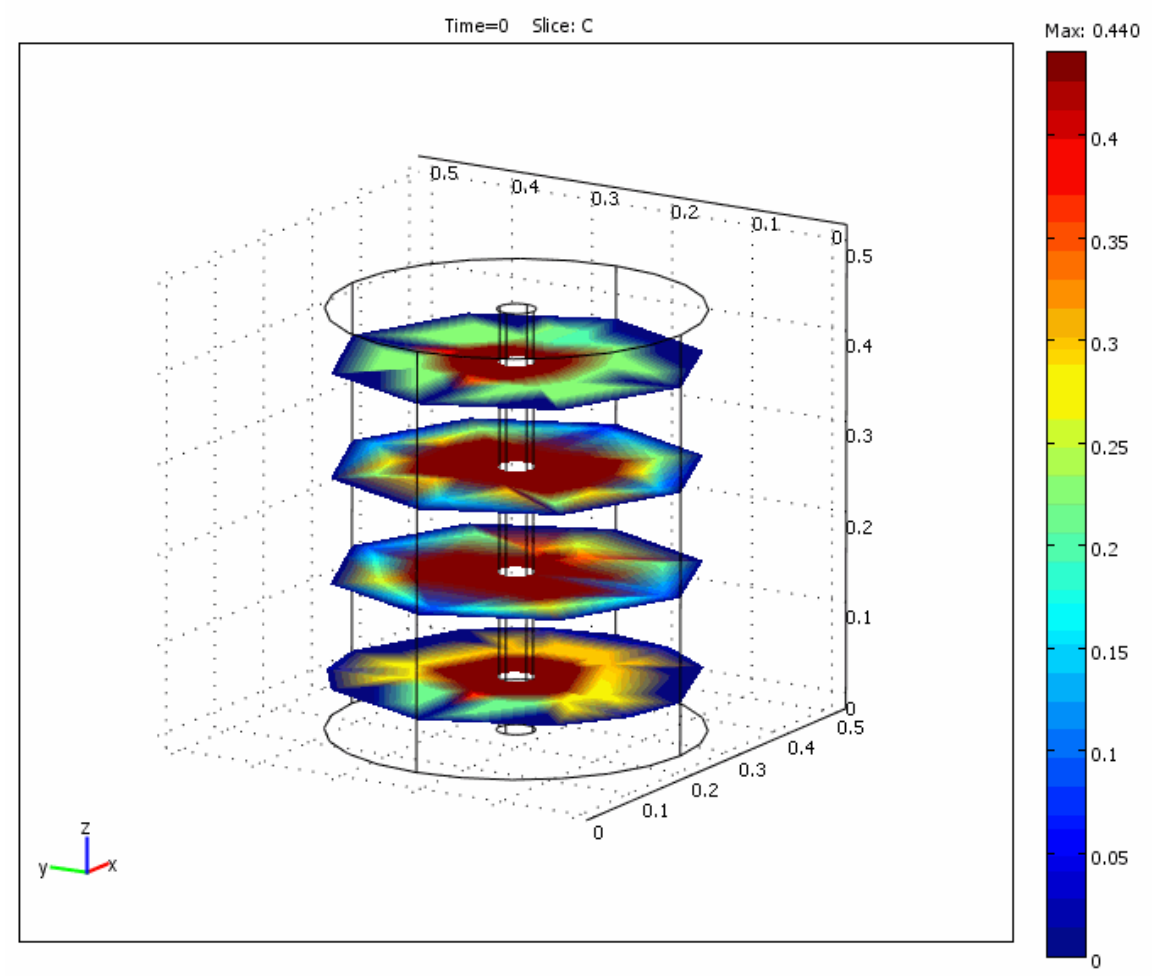

Fig. 5a: Concentration of contaminant at the beginning of the simulation at $t=0$ (Case 2)

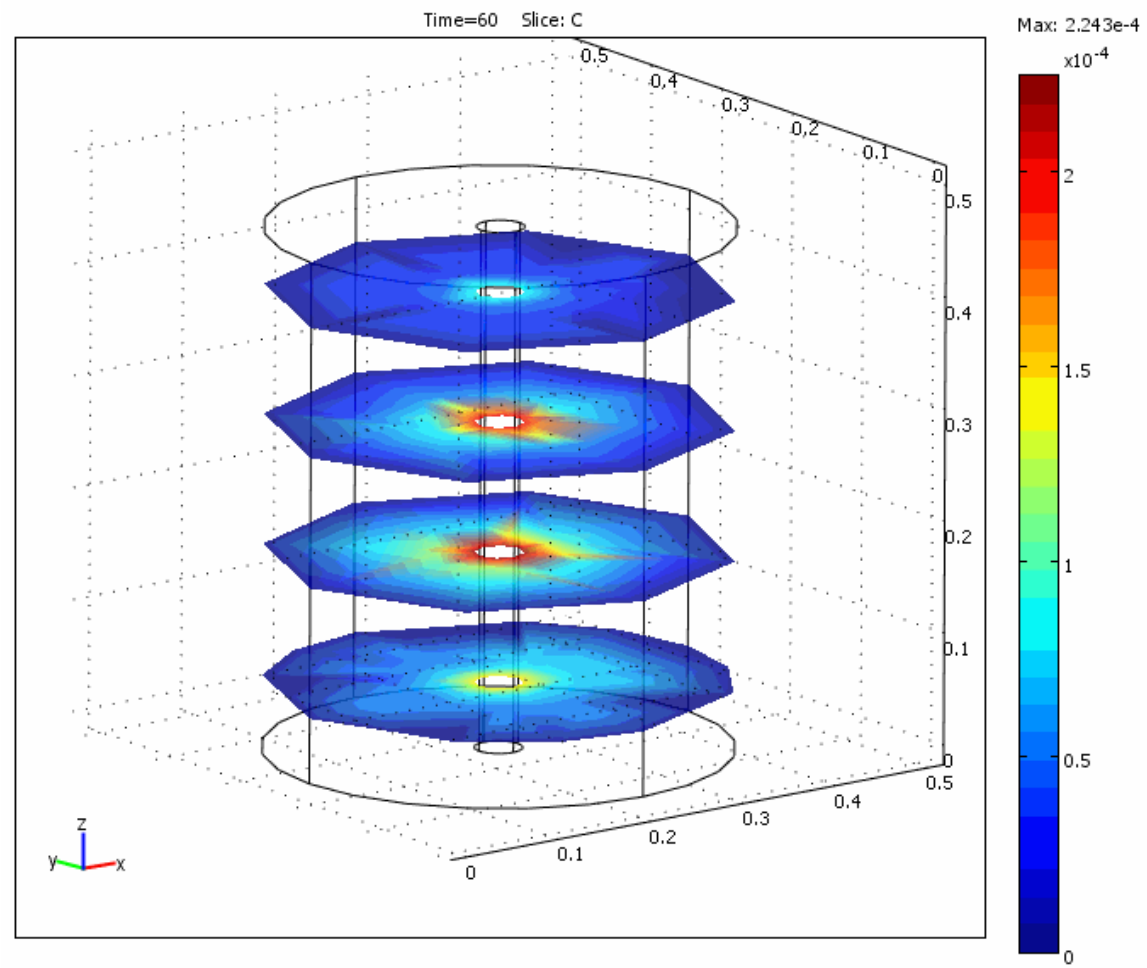

Fig. 5b: Concentration of contaminant after 60 hours (Case 2) 


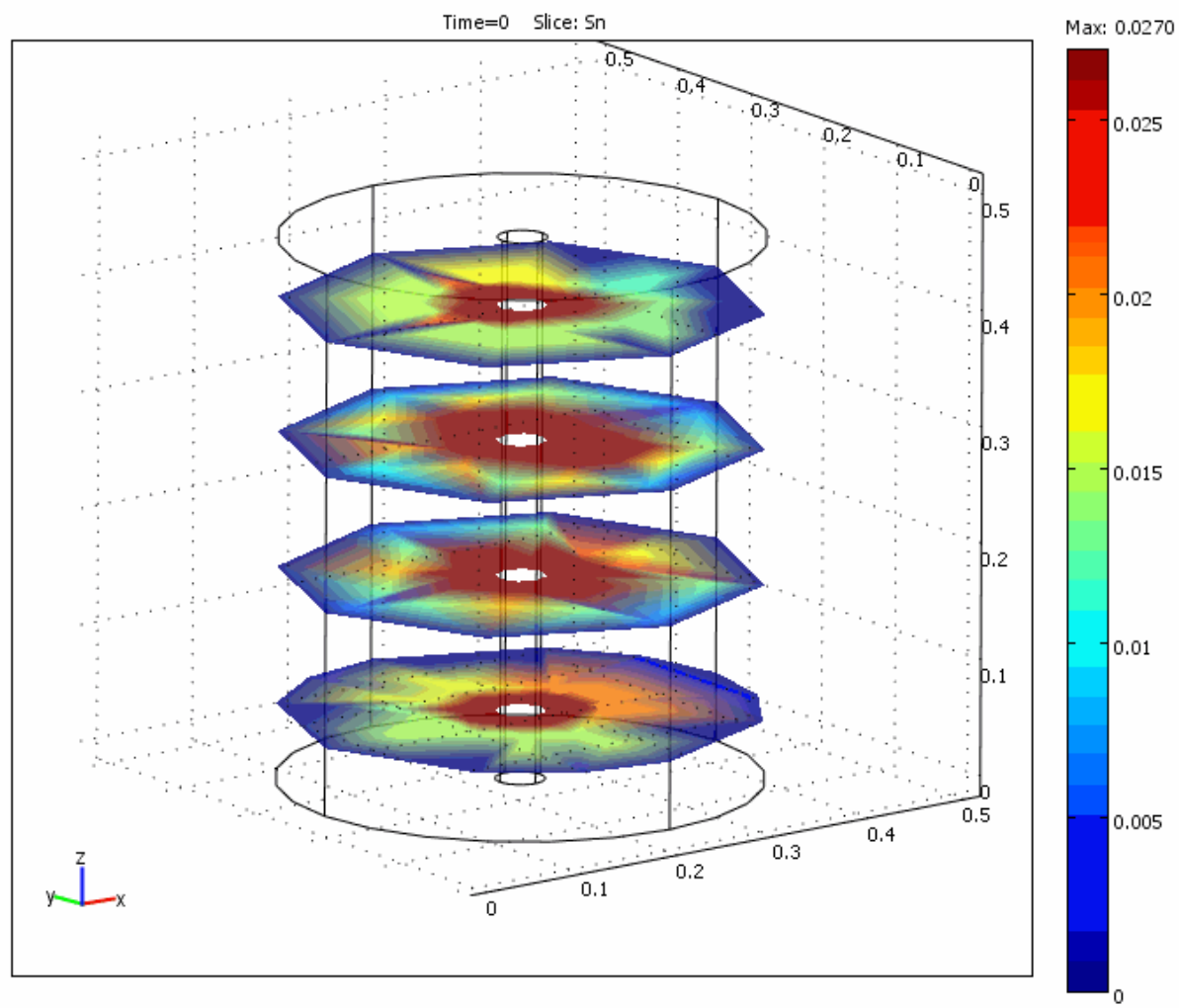

Fig. 6a: Saturation of NAPL at the beginning of the simulation at $t=0$ (Case 2)

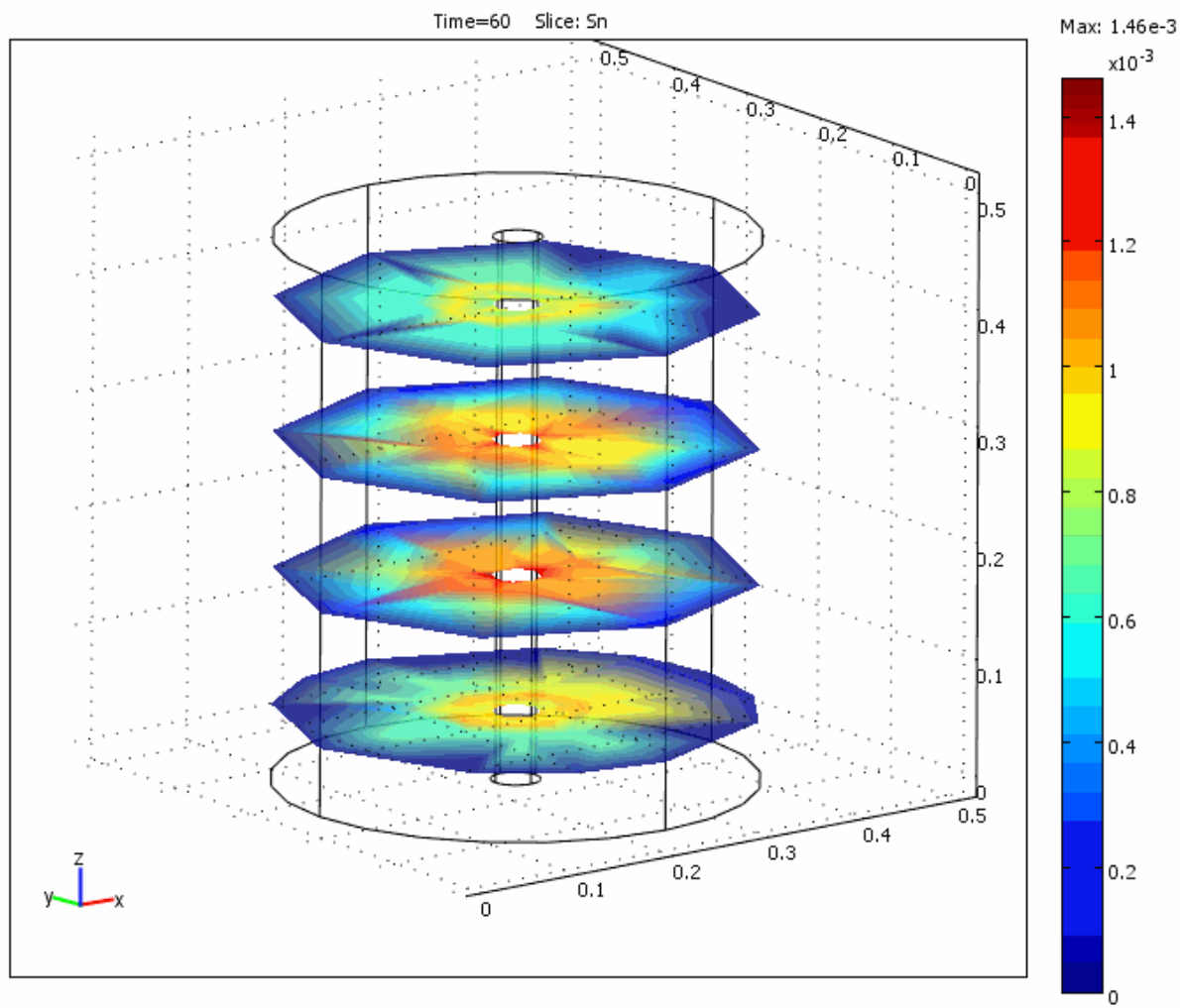

Fig. 6b: Saturation of NAPL after 60 hours (Case 2) 


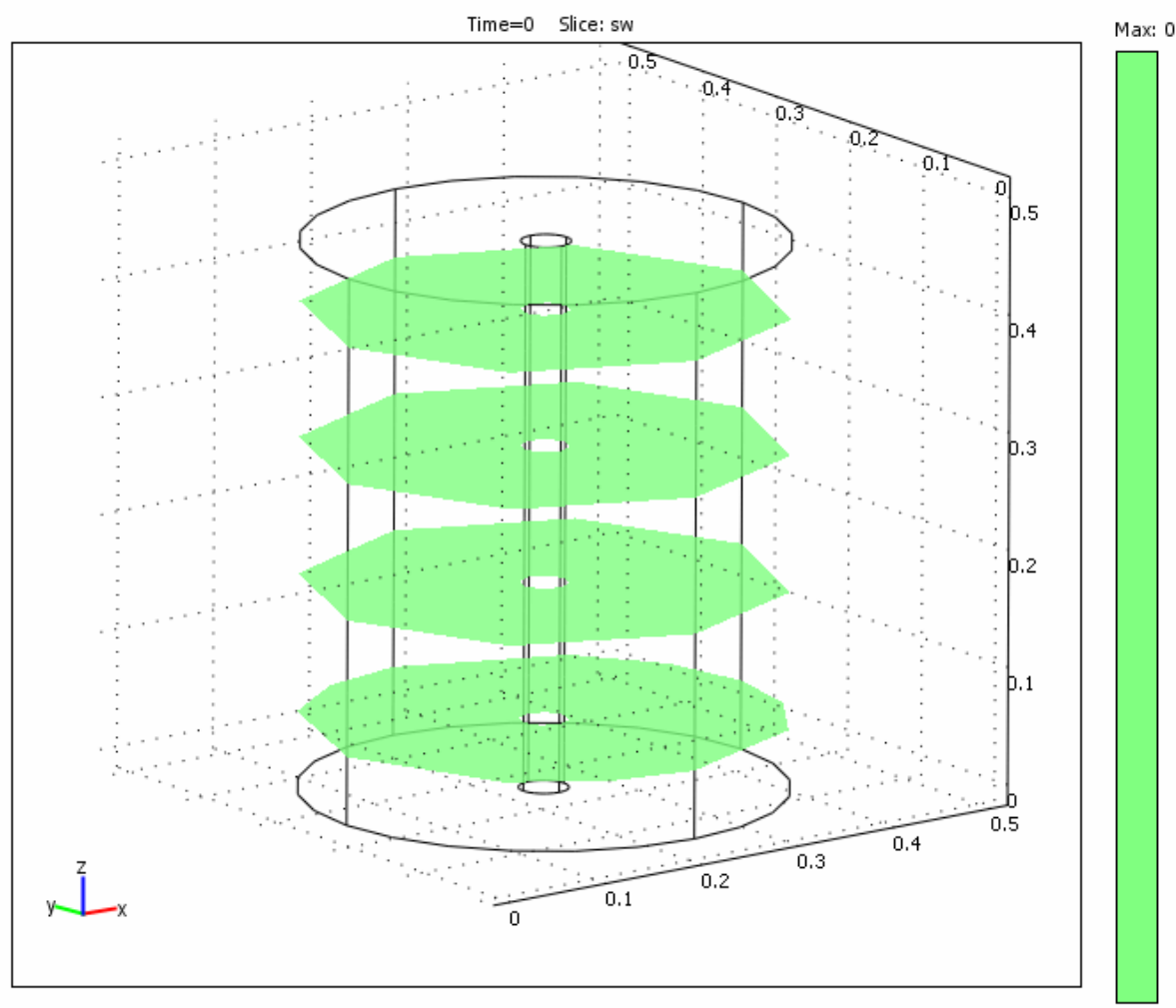

Fig. 7a: Saturation of water (aqueous) at the beginning of the simulation at $t=0$ (Case 2)

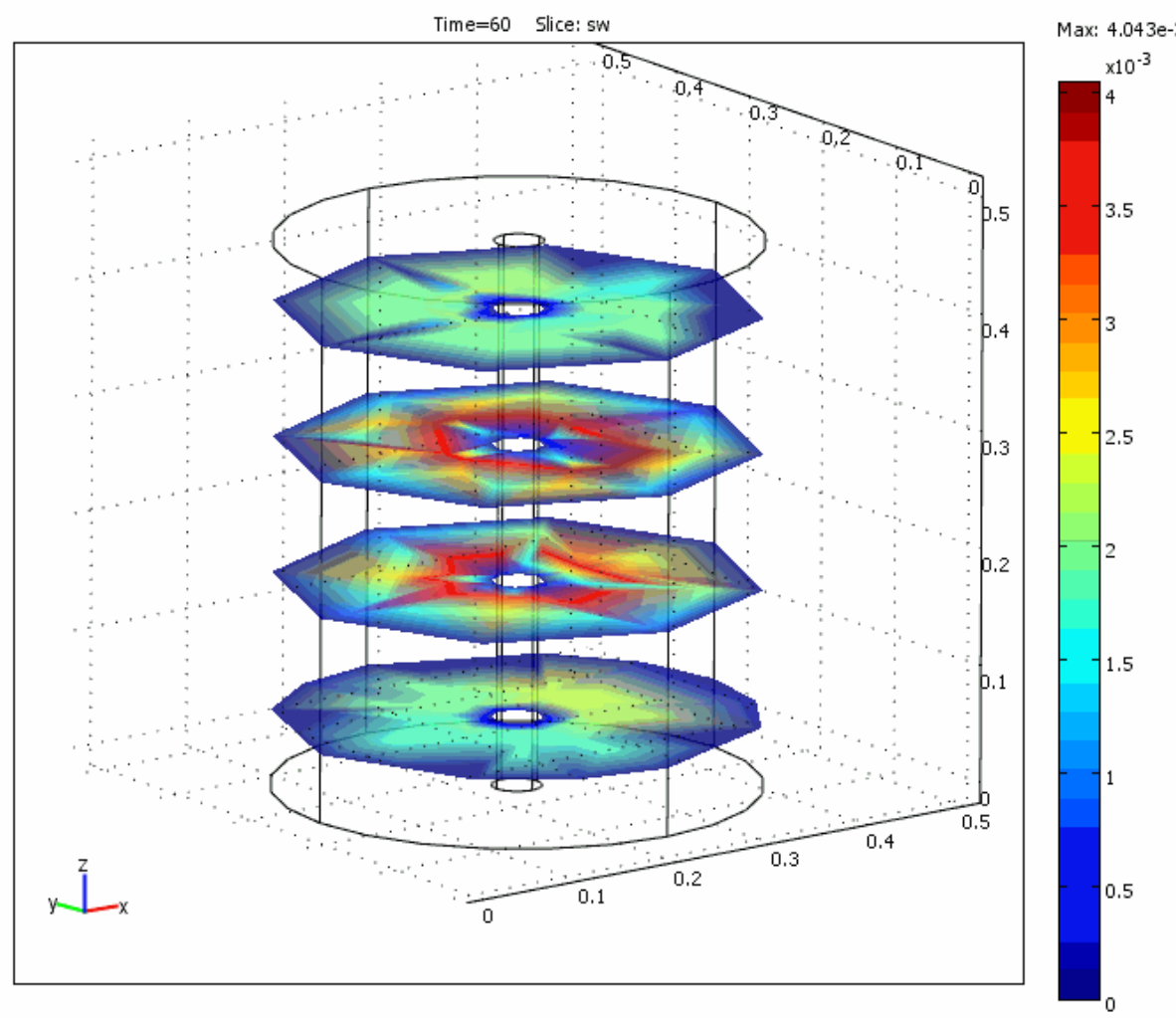

Fig. 7b: Saturation of water (aqueous) after 60 hours (Case 2) 


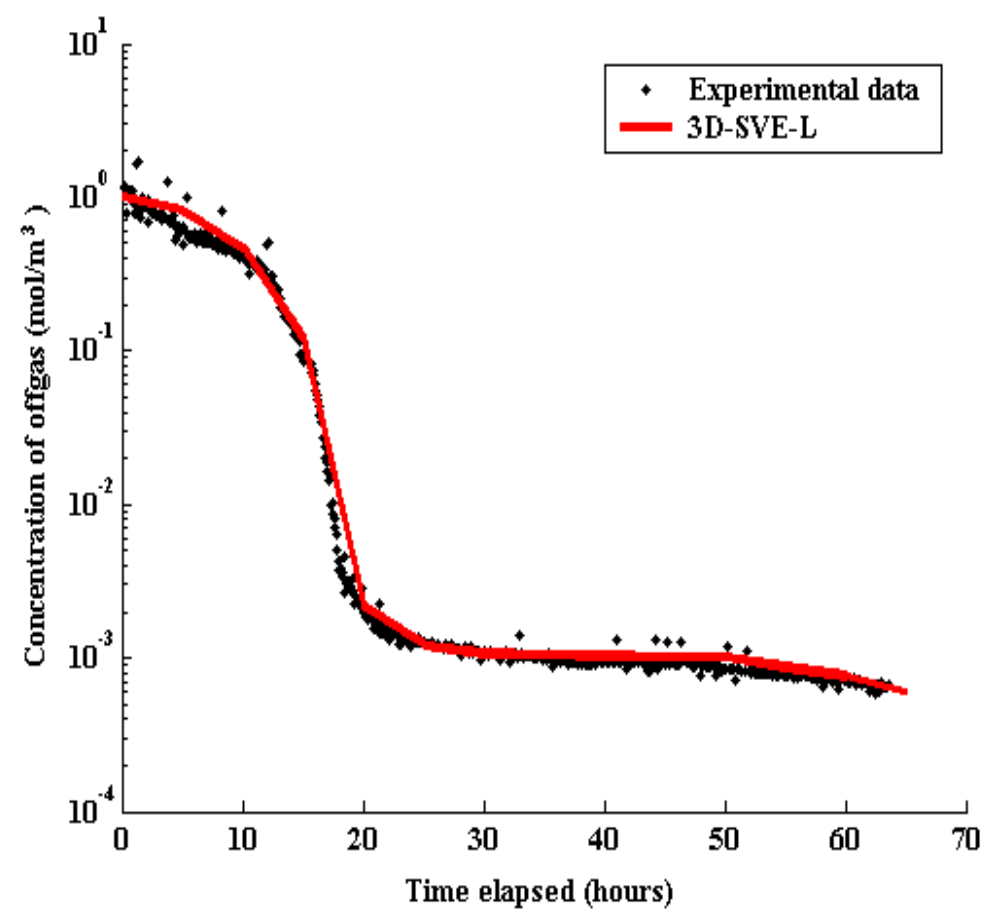

Fig. 8: Best fitting results for Elora Silt (Case 2)

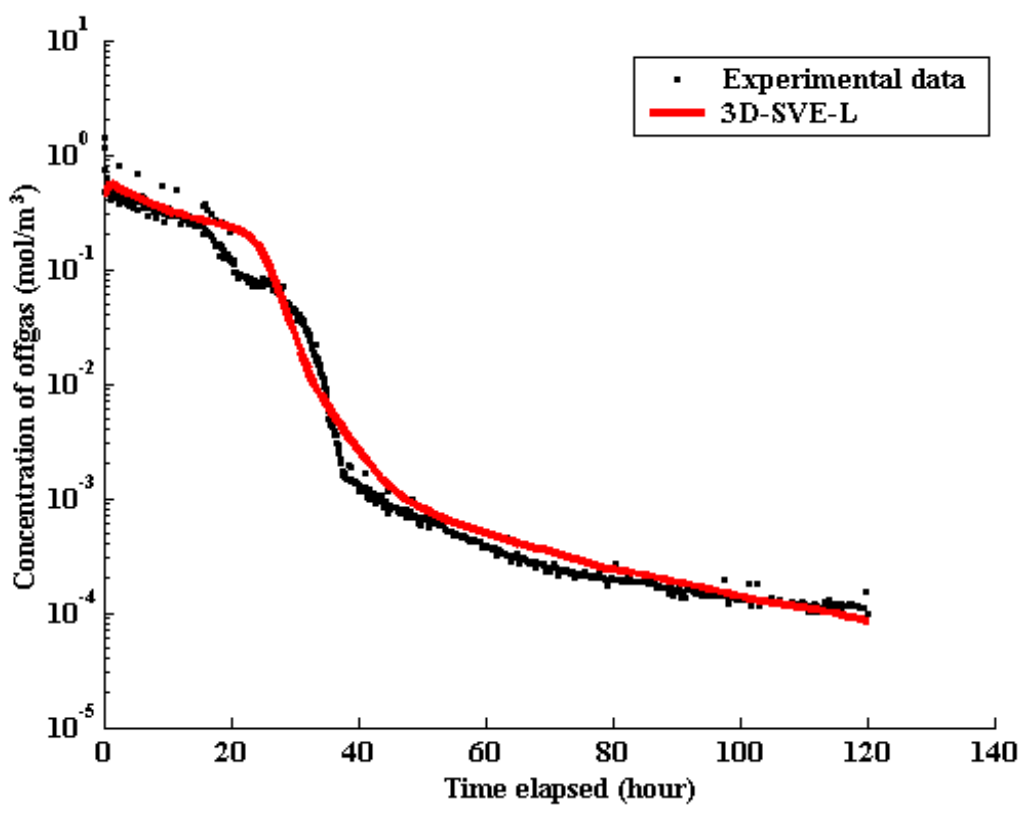

Fig. 9: Best fitting results for Elora Silt (Case 4) 


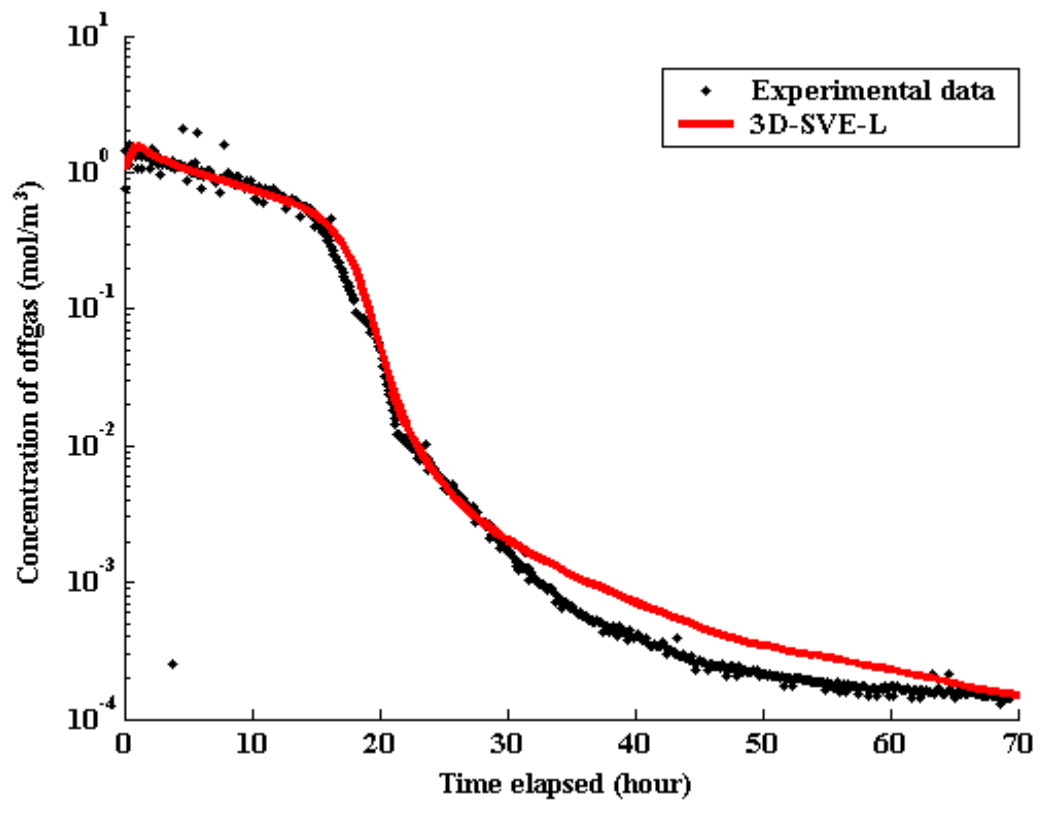

Figure 10 Best fitting results for Ottawa sand Elora Silt (Case 9)

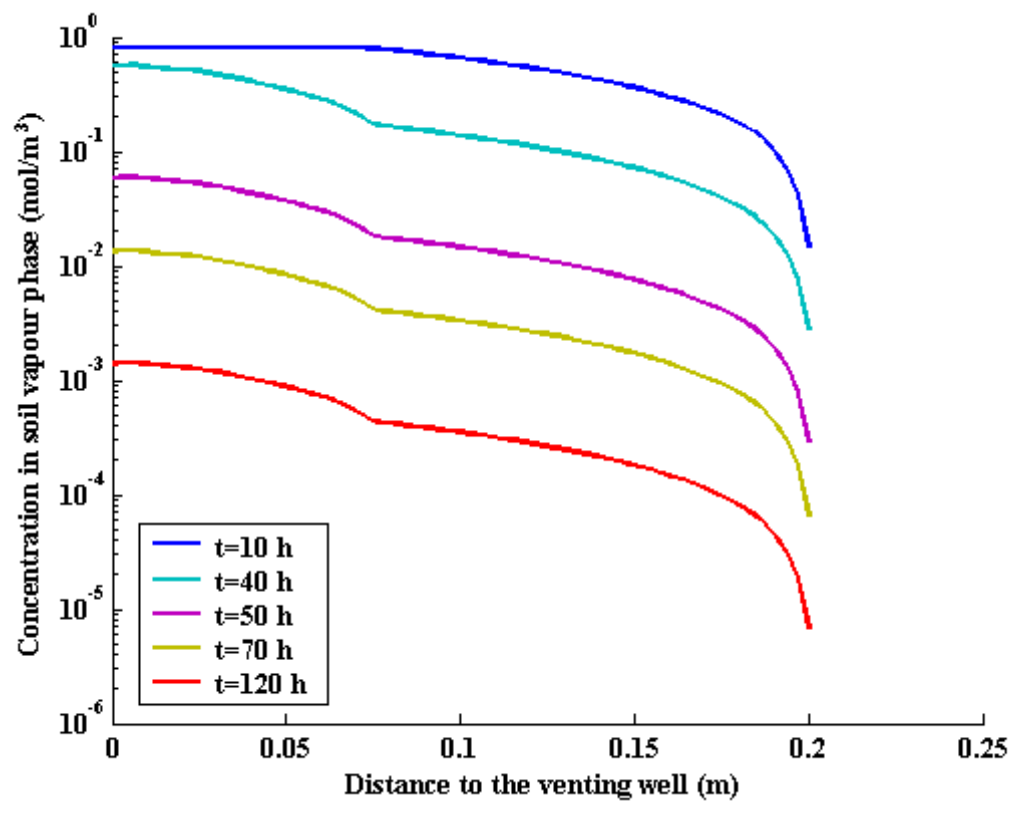

Figure 11: Concentration of Toluene in Soil Vapour Phase versus time for Case 4 


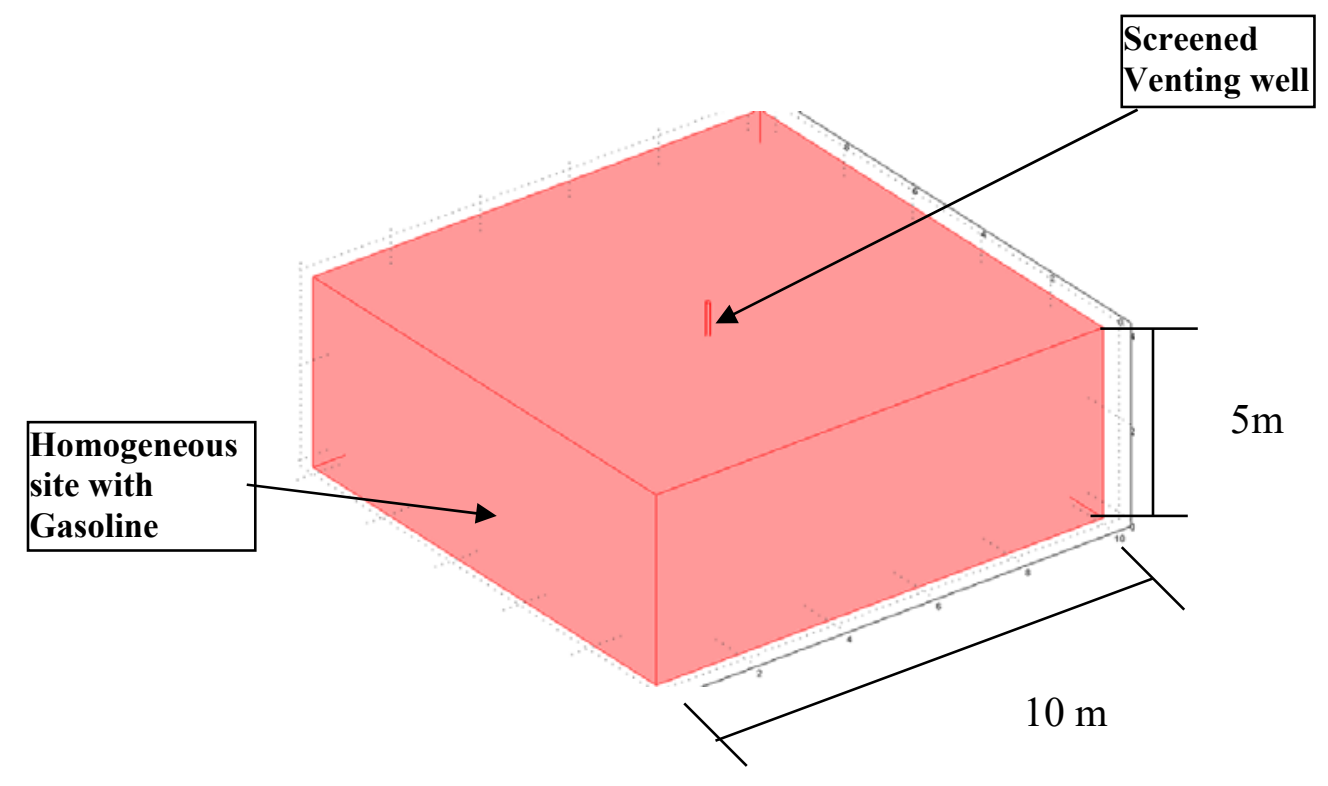

Figure 12 Schematic of the Simulated SVE Site Remediated by CRA in 1997

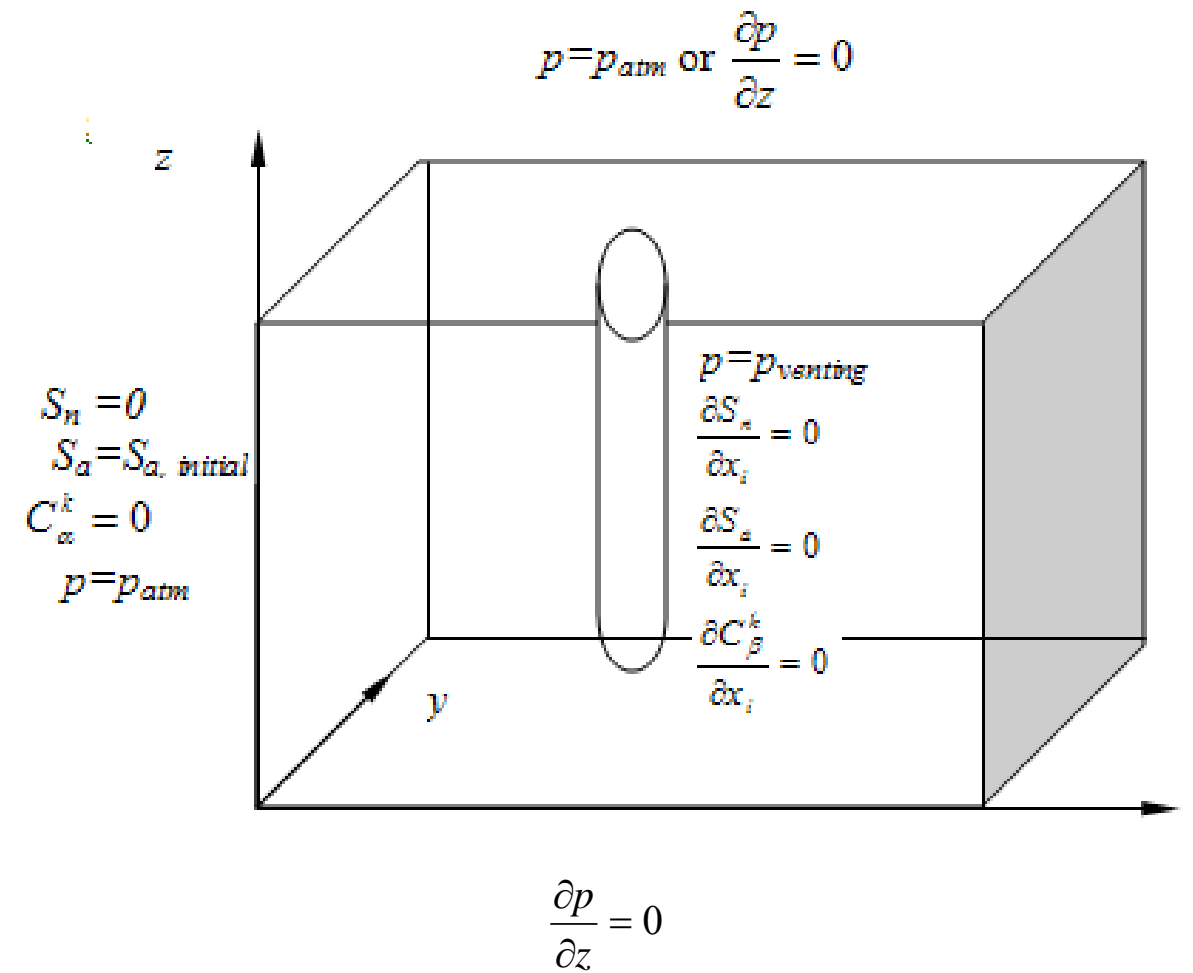

Figure 13: A schematic diagram of boundary conditions for the field case 


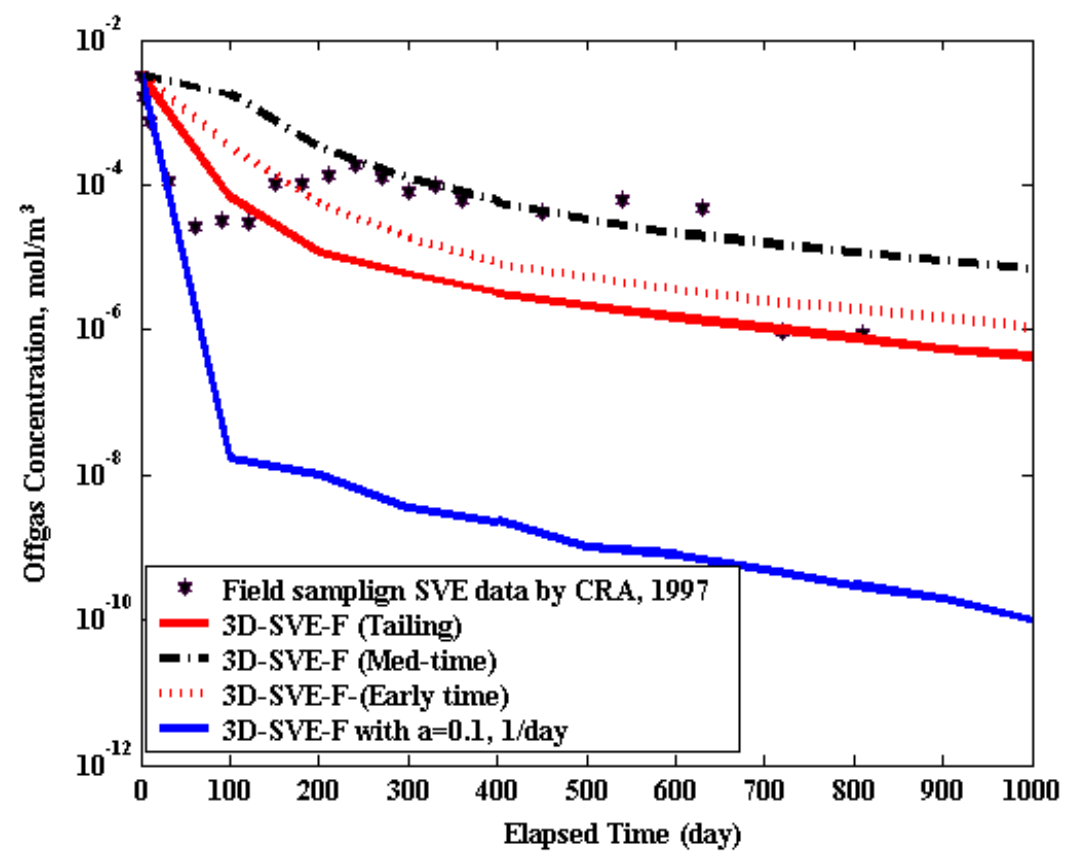

Figure 14: Fitting Results for Field SVE Operation

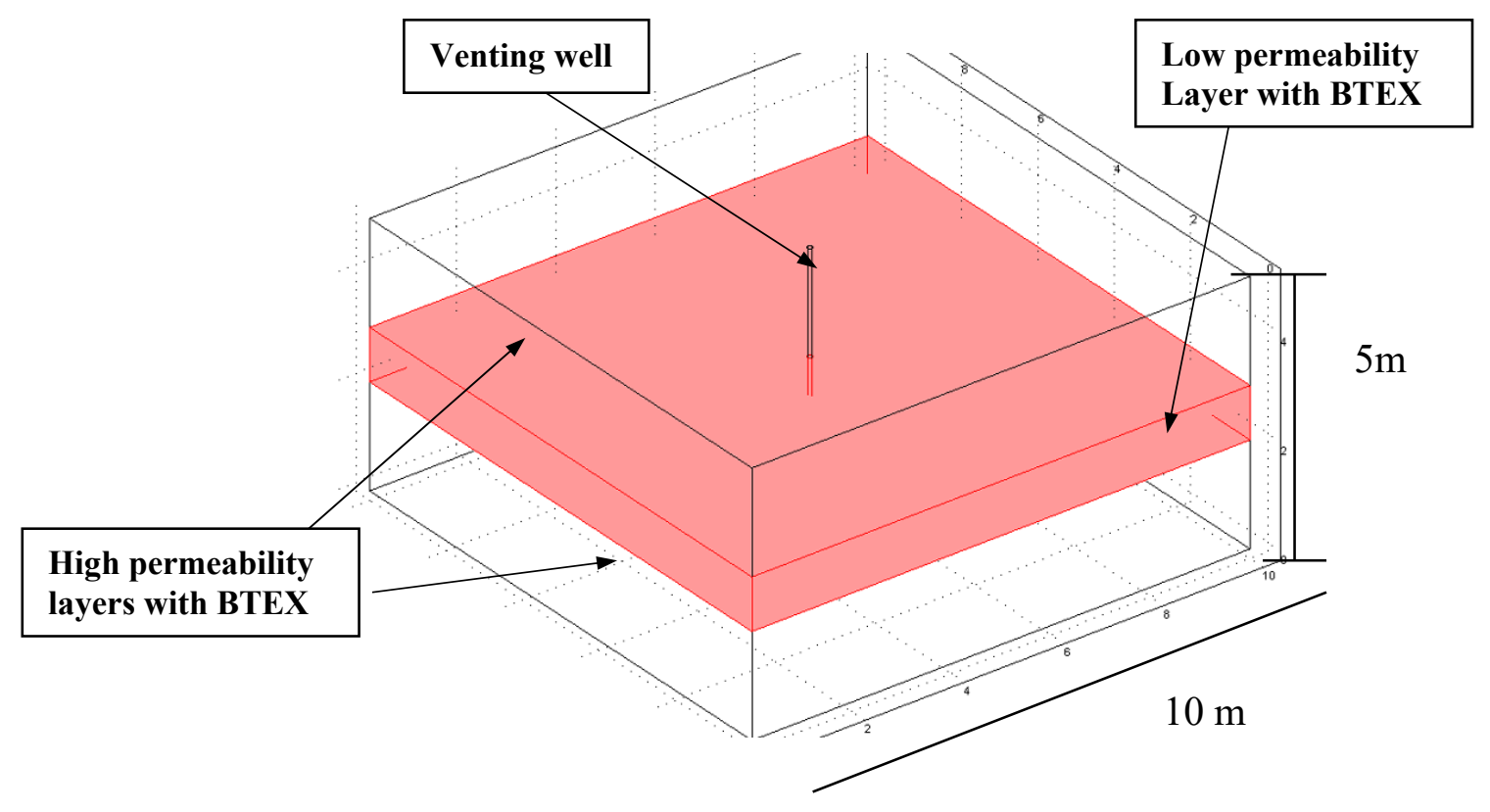

Figure 15 The Hypothetical Heterogeneous SVE Site 


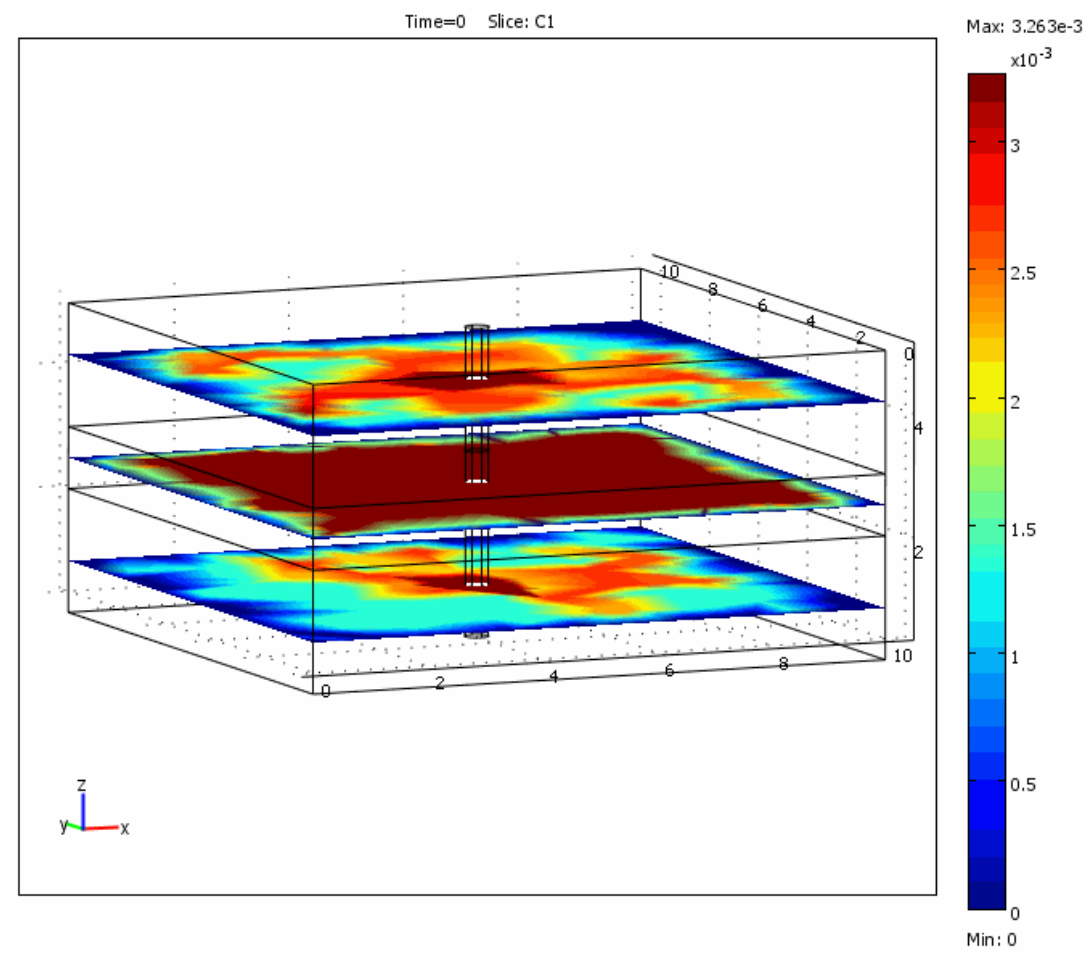

Figure 16a The Profile of Concentrations Distributed in Different Zones at $t=0$
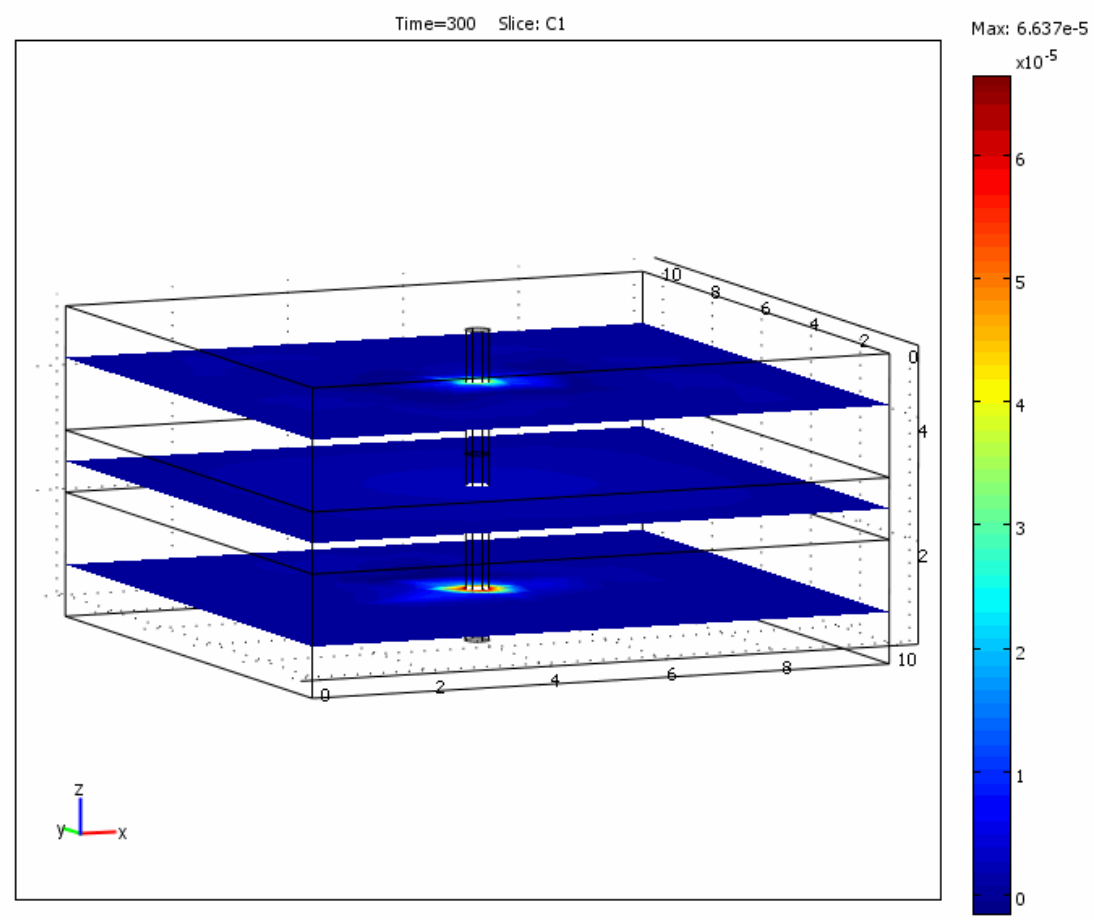

Figure 16b

The Profile of Concentrations Distributed in Different Zones at $\mathbf{t}=\mathbf{3 0 0 h}$ 


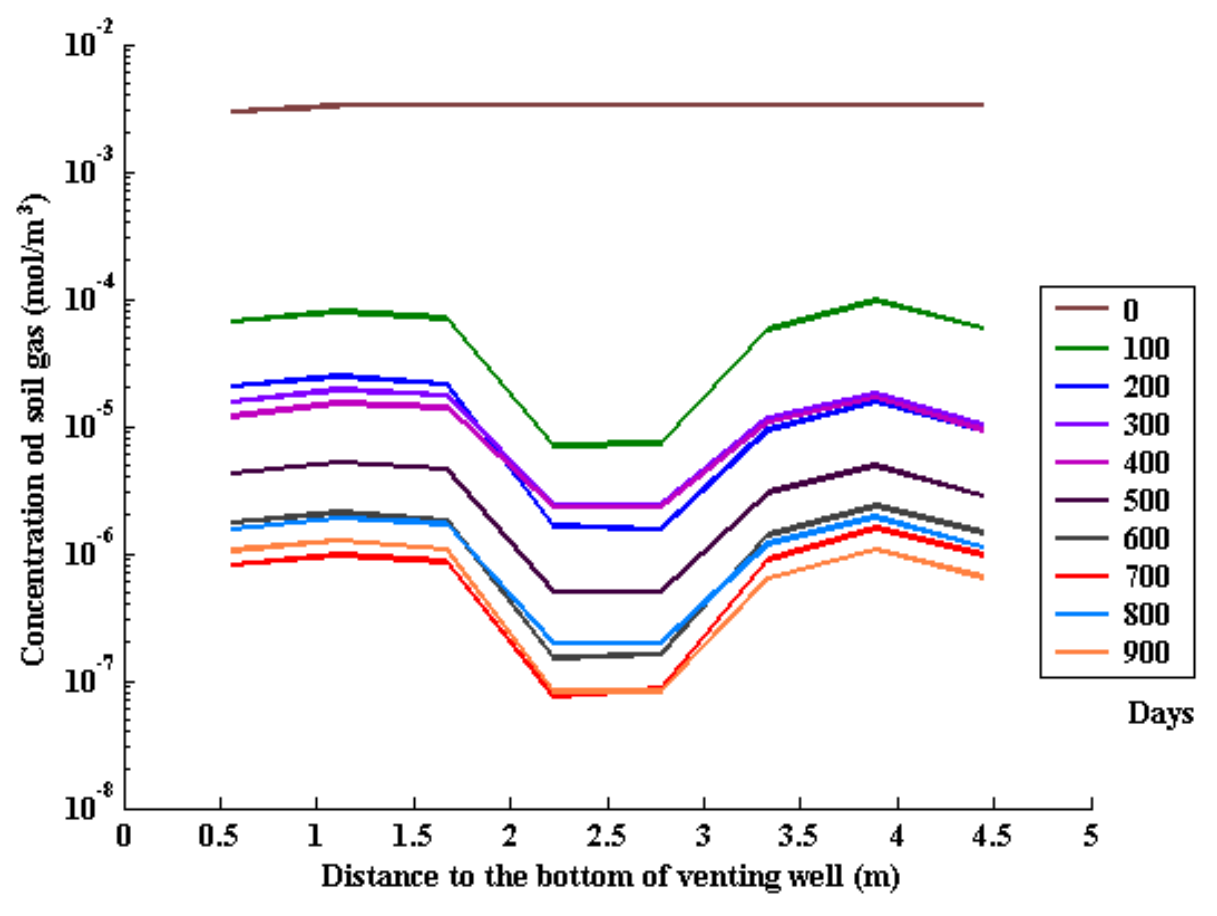

Figure 17 Concentration of Benzene in Soil Vapour versus Time along vertical line 0.05 m radially away from venting well 